\title{
Reciprocal Regulation of Mitochondrial Dynamics and Calcium Signaling in Astrocyte Processes
}

\author{
- Joshua G. Jackson ${ }^{1,2}$ and $\oplus^{-M i c h a e l ~ B . ~ R o b i n s o n ~}{ }^{1,2,3}$ \\ ${ }^{1}$ Children's Hospital of Philadelphia Research Institute, and ${ }^{2}$ Departments of Pediatrics and ${ }^{3}$ Systems Pharmacology and Experimental Therapeutics, \\ University of Pennsylvania, Pennsylvania 19104
}

We recently showed that inhibition of neuronal activity, glutamate uptake, or reversed- $\mathrm{Na}^{+} / \mathrm{Ca}^{2+}$-exchange with TTX, TFB-TBOA, or YM-244769, respectively, increases mitochondrial mobility in astrocytic processes. In the present study, we examined the interrelationships between mitochondrial mobility and $\mathrm{Ca}^{2+}$ signaling in astrocyte processes in organotypic cultures of rat hippocampus. All of the treatments that increase mitochondrial mobility decreased basal $\mathrm{Ca}^{2+}$. As recently reported, we observed spontaneous $\mathrm{Ca}^{2+}$ spikes with half-lives of $\sim 1 \mathrm{~s}$ that spread $\sim 6 \mu \mathrm{m}$ and are almost abolished by a TRPA1 channel antagonist. Virtually all of these $\mathrm{Ca}^{2+}$ spikes overlap mitochondria (98\%), and 62\% of mitochondria are overlapped by these spikes. Although tetrodotoxin, TFB-TBOA, or YM-244769 increased $\mathrm{Ca}^{2+}$ signaling, the specific effects on peak, decay time, and/or frequency were different. To more specifically manipulate mitochondrial mobility, we explored the effects of Miro motor adaptor proteins. We show that Mirol and Miro2 are both expressed in astrocytes and that exogenous expression of $\mathrm{Ca}^{2+}$-insensitive Miro mutants (KK) nearly doubles the percentage of mobile mitochondria. Expression of Miro $1{ }^{\mathrm{KK}}$ had a modest effect on the frequency of these $\mathrm{Ca}^{2+}$ spikes but nearly doubled the decay half-life. The mitochondrial proton ionophore, FCCP, caused a large, prolonged increase in cytosolic $\mathrm{Ca}^{2+}$ followed by an increase in the decay time and the spread of the spontaneous $\mathrm{Ca}^{2+}$ spikes. Photo-ablation of mitochondria in individual astrocyte processes has similar effects on $\mathrm{Ca}^{2+}$. Together, these studies show that $\mathrm{Ca}^{2+}$ regulates mitochondrial mobility, and mitochondria in turn regulate $\mathrm{Ca}^{2+}$ signals in astrocyte processes.

Key words: astrocyte; calcium; GCaMP; glutamate transport; Miro; mitochondria

\section{Significance Statement}

In neurons, the movement and positioning of mitochondria at sites of elevated activity are important for matching local energy and $\mathrm{Ca}^{2+}$ buffering capacity. Previously, we demonstrated that mitochondria are immobilized in astrocytes in response to neuronal activity and glutamate uptake. Here, we demonstrate a mechanism by which mitochondria are immobilized in astrocytes subsequent to increases in intracellular $\left[\mathrm{Ca}^{2+}\right]$ and provide evidence that mitochondria contribute to the compartmentalization of spontaneous $\mathrm{Ca}^{2+}$ signals in astrocyte processes. Immobilization of mitochondria at sites of glutamate uptake in astrocyte processes provides a mechanism to coordinate increases in activity with increases in mitochondrial metabolism.

\section{Introduction}

In the CNS, mitochondria accumulate at sites of elevated activity or metabolic demand, including presynaptic and postsynaptic

\footnotetext{
Received May 27, 2015; revised Sept. 11, 2015; accepted Sept. 30, 2015.

Author contributions: J.G.J. and M.B.R. designed research; J.G.J. performed research; J.G.J. contributed unpublished reagents/analytic tools; J.G.J. and M.B.R. analyzed data; J.G.J. and M.B.R. wrote the paper.

This work was supported by National Institute of Neurological Disorders and Stroke Grant R01 NS077773 to M.B.R., Institutional Intellectual Developmental Disabilities Research Center U54 HD086984 Cellular Neuroscience Core, and Biostatistics and Bioinformatics Core. We thank Dr. Mary Putt for statistical advice; Drs. Douglas Coulter and Hajime Takano for advice with imaging and data analysis; members of the M.B.R. and Coulter laboratories for their advice and suggestions during the conduct of this research; and John $0^{\prime}$ Donnell for helpful suggestions.

The authors declare no competing financial interests.

Correspondence should be addressed to Dr. Michael B. Robinson, Department of Pediatrics, 502N, Abramson Research Building, 3615 Civic Center Boulevard, Philadelphia, PA 19104-3779. E-mail: Robinson@mail.med.upenn.edu.
}

compartments, growth cones, nodes of Ranvier, and near clusters of glutamate transporters (GLT-1) in the astrocyte processes that appose synapses (Li et al., 2004; Ohno et al., 2011; Schwarz, 2013; Jackson et al., 2014). Recently, we found that mitochondria are present in the processes of astrocytes and that their mobility is inhibited by neuronal activity, glutamate uptake, and reversed $\mathrm{Na}^{+} / \mathrm{Ca}^{2+}$-exchange (Genda et al., 2011; Jackson et al., 2014). Further, we demonstrated that neuronal activity increased the probability that mitochondria approach clusters of the glial glutamate transporter GLT-1 within astrocyte processes that appose VGLUT1 puncta, suggesting that regulation of mitochondrial 
mobility may represent a mechanism to retain mitochondria near sites of glutamate uptake in astrocytes. Here we sought to uncover molecular mechanisms regulating the immobilization of mitochondria and the consequences of inhibiting their regulated distribution.

In neurons, mitochondria accumulate at sites of elevated activity in part via the actions of the Miro (RhoT) proteins. There are two Miro isoforms (Mirol and Miro2) that share $\sim 60 \%$ identity (Fransson et al., 2003). These $\mathrm{Ca}^{2+}$-sensitive adaptor proteins link the mitochondria to the motor protein kinesin-1 through Trak1/2 (Milton) proteins (Stowers et al., 2002; Glater et al., 2006; Brickley and Stephenson, 2011). Elevations of $\left[\mathrm{Ca}^{2+}\right]_{i}$ result in a Miro-mediated disengagement of the mitochondria from the motor apparatus through mechanisms that are incompletely understood (Macaskill et al., 2009; Wang and Schwarz, 2009). Little is known about the mechanisms regulating mitochondrial movement and distribution in astrocyte processes (Stephen et al., 2014; Benjamin Kacerovsky and Murai, 2015).

Although astrocytes are not electrically excitable, they are heavily integrated into the neuronal circuitry in which they reside (for review, see Barres, 2008; Halassa and Haydon, 2010). They possess numerous processes and a large complement of receptors that allow them to sense and respond to extracellular stimuli. The activation of many of these receptors is coupled to increases in intracellular $\left[\mathrm{Ca}^{2+}\right]$, either through flux across the plasma membrane (ionotropic receptors, reversed $\mathrm{Na}^{+} / \mathrm{Ca}^{2+}$ exchange) or via release from intracellular stores (metabotropic receptors, etc.) (for review, see Volterra et al., 2014; Rusakov, 2015). The diversity of these signals (localization, amplitude, kinetics, and frequency) allows a common signal to potentially couple to distinct cellular activities. Indeed, elevations of astrocyte $\left[\mathrm{Ca}^{2+}\right]_{\mathrm{i}}$ have been implicated in diverse physiologic functions, including regulation of local blood flow (Petzold et al., 2008; Schummers et al., 2008; Petzold and Murthy, 2011; Otsu et al., 2015), release of transmitter (Nedergaard, 1994; Parpura et al., 1994; Marchaland et al., 2008; Navarrete et al., 2013), and synaptic plasticity (Di Castro et al., 2011; Min and Nevian, 2012). Understanding how these local $\mathrm{Ca}^{2+}$ signals are generated, compartmentalized, and the consequences of these signals is crucial to understanding the physiologic function of astrocytes.

Mitochondria play complex, interdigitated roles in cellular physiology. In addition to providing the ATP necessary to maintain ionic gradients (via the tricarboxylic acid [TCA] cycle and oxidative phosphorylation), mitochondria can also buffer cytosolic $\mathrm{Ca}^{2+}$ (Rizzuto et al., 2012; for review, see Williams et al., 2013b). The ability of mitochondria to accumulate $\mathrm{Ca}^{2+}$ is dependent upon the large electrochemical potential of the mitochondria (Kirichok et al., 2004). Accumulated $\mathrm{Ca}^{2+}$ is released back into the cytosol via mitochondrial $\mathrm{Na}^{+} / \mathrm{Ca}^{2+}$ exchangers (Baron and Thayer, 1997). $\mathrm{Ca}^{2+}$ uptake stimulates TCA cycle flux (Wan et al., 1989) via stimulation of the $\mathrm{Ca}^{2+}$-sensitive dehydrogenases (Denton et al., 1972). Indeed, constitutive $\mathrm{IP}_{3}$ receptor-mediated transfer of $\mathrm{Ca}^{2+}$ from the endoplasmic reticulum to mitochondria is essential for optimal mitochondrial performance (Cárdenas et al., 2010).

Here, we examine a role for $\mathrm{Ca}^{2+}$ signaling in regulating the immobilization of mitochondria within the processes of astrocytes. We examine mechanisms that mediate increases in $\left[\mathrm{Ca}^{2+}\right]_{\mathrm{i}}$ and potential roles for Miro proteins in mediating the $\mathrm{Ca}^{2+}$ dependent arrest of mitochondria within these processes. Last, we explore how modulating mitochondrial $\mathrm{Ca}^{2+}$ buffering or positioning influences $\mathrm{Ca}^{2+}$ signaling within the astrocytes.

\section{Materials and Methods}

cDNA contructs. pRK5-myc-Mirol (Addgene plasmid \#47888), pRK5myc-Miro1 E208K/E328K (Miro1 ${ }^{\text {KK}}$; Addgene plasmid \#47894), pRK5myc-Miro2 (Addgene plasmid \#47891), and pRK5-myc-Miro2 E208K/ E328K (Miro2 ${ }^{\mathrm{KK}}$; Addgene plasmid \#47900) (Fransson et al., 2003; Fransson et al., 2006) were generated by Pontus Aspenström (Karolinska Institute, Stockholm, Sweden). EGFP-Miro1, EGFP-Miro2, EGFPMirol $^{\text {KK }}$ (EGFP-Miro 1 ${ }^{\text {E208K/E328K}}$ ) and EGFP-Miro2 ${ }^{\text {KK }}$ (EGFPMiro2 $\left.{ }^{\mathrm{E} 208 \mathrm{~K} / \mathrm{E} 328 \mathrm{~K}}\right)$ are all N-terminal fusions with EGFP and were constructed using PCR amplification from their myc-Miro cognates. pGP-CMV-GCaMP6s was a gift from Douglas Kim (Addgene plasmid \#40753) (Chen et al., 2013). pN1 LCK-GCaMP5G was a gift from Baljit Khakh (Addgene plasmid \#34924) (Akerboom et al., 2012). LCKGCaMP6s was generated by transferring the LCK-derived membranetethering domain from LCK-GCaMP5G in-frame with GCaMP6s. pDsRed2-mito was purchased from Clontech (catalog \#632421). $\mathrm{pGFA}_{\mathrm{ABC1D}}$ :DsRed2mito was generated by replacing the CMV promoter of pDsRed2-mito with the minimal GFAP promoter $\left(\mathrm{GFA}_{\mathrm{ABC1D}}\right)$ from pTY-GFA ${ }_{\mathrm{ABC1D}}$-gp43mcherry. pTY-GFA $\mathrm{ABC1D}_{\mathrm{D}}$ :mCherry has been described previously (Jackson et al., 2014). pEGFP-mito (a gift from Dr. Stanley Thayer-University of Minnesota, Minneapolis) is a fusion of EGFP with the mitochondrial matrix targeting sequence from CoxVIII and has been shown to result in specific targeting of EGFP into mitochondria (Rizzuto et al., 1992; Wang et al., 2003).

Antibodies. Rabbit anti-Mirol antibody was purchased from SigmaAldrich (Atlas; catalog \#PA010687). Rabbit anti-Miro1 (for immunoblot) was purchased from Novus Biologicals. Mouse anti-Miro2 (catalog \#75-365, RRID:AB_2315894) was purchased from Neuromab. Highly cross-adsorbed secondary antibodies conjugated to AlexaFluor dyes were purchased from Invitrogen. TTX was purchased from Alomone Labs. FCCP (carbonyl cyanide 4-(trifluoromethoxy)phenylhydrazone)), A96 7079, (3S)-3-[[3-[[4-(trifluoromethyl)benzoyl] amino]phenyl]methoxy]-Laspartic acid (TFB-TBOA), N-[(3-aminophenyl) methyl]-6-[4-[(3-fluorophenyl) methoxy] phenoxy]-3-pyridine carboxamide dihydrochloride (YM-244769) were purchased from Tocris Bioscience. All other reagents were purchased from VWR.

Slice culture and transfections. All procedures involving animals were conducted with the approval of the Institutional Animal Care and Use Committee at the Children's Hospital of Philadelphia. Organotypic hippocampal cultures were prepared as described previously (Benediktsson et al., 2005 Jackson et al., 2014). Briefly, postnatal rat pups (p8-p12) of either sex were decapitated and their brains rapidly removed into icecold $\left(4^{\circ} \mathrm{C}\right)$ sucrose-aCSF composed of the following (in $\mathrm{mM}$ ): 280 sucrose, $5 \mathrm{KCl}, 2 \mathrm{MgCl}_{2}, 1 \mathrm{CaCl}_{2}, 20$ glucose, and 10 HEPES. Hippocampi were isolated and sliced into $300 \mu \mathrm{m}$ sections using a McIlwain-type tissue chopper (Brinkman Instruments). Three or four slices were placed onto each $0.4 \mu \mathrm{m}$ Millicell tissue culture insert (PICMORG50; Millipore) in six-well plates, $1 \mathrm{ml}$ of medium containing the following: $50 \% \mathrm{Neu}-$ robasal medium, 25\% horse serum, 25\% HBSS, supplemented with 10 mм HEPES, 36 mm glucose, 2 mм glutamine, $1 \times$ Gem21-Neuroplex supplement, $10 \mathrm{U} / \mathrm{ml}$ penicillin, and $100 \mu \mathrm{g} / \mathrm{ml}$ streptomycin, $\mathrm{pH} 7.2-$ 7.3 , placed underneath each insert. One-third of the media was changed every $2 \mathrm{~d}$. Slices were maintained in a humidified incubator with $5 \%$ $\mathrm{CO}_{2} / 95 \%$ air at $37^{\circ} \mathrm{C}$. Slices were allowed to recover for $2 \mathrm{~d}$ before transfection via a Helios Gene-Gun (Bio-Rad) (McAllister, 2004; Benediktsson et al., 2005). Gene gun bullets were generated as follows: cDNAs (10 $\mu \mathrm{g}$ total) were combined with $8-10 \mathrm{mg}$ of $1.0 \mu \mathrm{m}$ gold particles (Bio$\mathrm{Rad}$ ) in a solution containing $0.05 \mathrm{M}$ spermidine, and $1 \mathrm{M} \mathrm{CaCl}_{2}$ in 0.02 $\mathrm{mg} / \mathrm{ml}$ polyvinylpyrrolidone 20 . This suspension was used to coat Teflon tubing (Tefzel; Bio-Rad) that was subsequently cut and loaded into the Gene-Gun. The cDNA-coated gold particles were shot using highpressure helium (120-140 psi) into cultured slices in inserts sitting on warmed agarose slabs. Although the smaller gold particles improve selectivity for transducing astrocytes (Benediktsson et al., 2005), we also always included at least one construct in which a GFAP promoter is used to control expression (see below). These cells are always astrocytes as defined by expression of glutamine synthetase or GFAP (Jackson et al., 2014). 
Astrocyte cultures. Primary cultures of astrocytes were prepared as previously described (Garlin et al., 1995). Briefly, neonatal (P0-P3) rat pups of either sex were decapitated and their brains placed into ice-cold HEPES-buffered Hanks solution. Cortices were isolated and meninges removed. Cortices were minced into smaller pieces and treated with trypsin for $20 \mathrm{~min}$ at $37^{\circ} \mathrm{C}$ in $5 \% \mathrm{CO}_{2} / 95 \%$ air. Trypsinization was terminated by washing in HBSS. Tissue was triturated in warm media $(10 \%$ heat-inactivated FBS, 10\% Ham's F-12 medium, and 80\% DMEM with $0.24 \%$ penicillin/streptomycin) through a series of subsequently smaller pipets. Dissociated tissue was plated into T75 flasks (BD Falcon). Once cells reached confluence $(\sim 7 \mathrm{~d}), \mathrm{A} 2 \mathrm{~B} 5$-positive cells were removed by incubating with anti-A2B5 antibody and rabbit complement for $45 \mathrm{~min}$. Cultures were then replated onto $6 \mathrm{~cm}$ dishes (BD Falcon) and harvested 5 d later.

Immunoblotting. Cortical tissue was harvested from adult male Sprague-Daley rats after death by decapitation to avoid effects of anesthetic agents. Tissue was homogenized in RIPA buffer $(150 \mathrm{~mm} \mathrm{NaCl}, 1$ mм EDTA, 100 mм Tris-HCl, $1 \%$ Triton X-100, and 1\% sodium deoxycholate, $\mathrm{pH}$ 7.4) plus protease and phosphatase inhibitors $(1 \mu \mathrm{g} / \mathrm{ml}$ leupeptin, $260 \mu \mathrm{M}$ PMSF, $1 \mu \mathrm{g} / \mathrm{ml}$ aprotonin, $1 \mathrm{~mm}$ iodoacetamide, $10 \mathrm{~mm}$ $\mathrm{NaF}$, and $1 \mathrm{~mm}$ sodium orthovanadate; $18.5 \mathrm{ml} / \mathrm{g}$ wet weight). Homogenates were rotated on a shaker for $1 \mathrm{~h}$ at $4^{\circ} \mathrm{C}$ and then cleared by centrifugation at $13,000 \times g$ for $30 \mathrm{~min}$ at $4^{\circ} \mathrm{C}$. Protein concentration was analyzed (bicinchorinic acid protein assay kit, Thermo Scientific). For analysis of proteins present in primary cultures of rat astrocytes, cultures were lysed in RIPA (as above). Proteins (including rainbow molecular weight marker; GE Healthcare) were resolved using 8\% SDSpolyacrylamide gels, transferred to PVDF membranes (PVDF-FL; Millipore), and blocked for $1 \mathrm{~h}$ at $25^{\circ} \mathrm{C}$ in TBS-T (50 mM Tris, $\mathrm{pH} 8.0,150 \mathrm{~mm}$ $\mathrm{NaCl}, 0.2 \%$ Tween 20 ) containing $5 \%$ nonfat dry milk (Carnation; Nestle). Membranes were then probed with rabbit anti-Mirol (1:2000) and mouse anti-Miro2 (1:100). Membranes were washed $3 \times$ in TBS-T containing $1 \%$ nonfat dry milk. Membranes were probed with fluorescent dye-conjugated secondary antibodies (goat anti-Rb 688 or goat antimouse 800; 1:10,000; LI-COR Biosciences). Protein bands were visualized using an Odyssey infrared imager (LI-COR Biosciences).

Immunohistochemistry. Immunohistochemical analyses of organotypic cultures of rat hippocampus were conducted as previously described (Jackson et al., 2014). Slices were transfected with pTY$\mathrm{GFA}_{\mathrm{ABC1D}}$ :mCherry and EGFP-mito. Two days after transfection, tissues were fixed by immersion in $4 \%$ PFA in PBS $(0.1 \mathrm{M})$. Tissue was processed as free-floating sections for subsequent immunostaining. Sections were extracted for $1 \mathrm{~h}$ in a solution of PBS and 1\% Triton X-100 at room temperature. Sections were blocked in $5 \%$ goat serum for $1 \mathrm{~h}$ at room temperature and incubated with primary antibodies against Mirol (1: 100; Sigma-Aldrich) or Miro2 (1:100; Neuromab) for $2 \mathrm{~d}$ at $4^{\circ} \mathrm{C}$ in a solution containing $1 \%$ Triton X-100 and $5 \%$ goat serum. The sections were rinsed three times for 15 min each in PBS and subsequently incubated overnight with secondary antibody (highly cross-adsorbed goat anti-rabbit or anti-mouse AlexaFluor-633; Invitrogen). Slices were rinsed three times for $15 \mathrm{~min}$ each in PBS before mounting on precoated slides (Superfrost Plus, Fisher Scientific) with aqueous mounting medium (Vectashield; Vector Laboratories). Sections were imaged on a laser confocal microscope (Olympus FV1000). To avoid potential bleed through of fluorophores, images were collected in sequential scan mode using the 488,546 , or 633 excitation lines to independently excite EGFP, mCherry, or AlexaFluor633, respectively.

Live slice imaging. Two days after transfection, slices were excised from the membrane supports and placed face-down in a flow-through chamber (RC21; Warner Instruments). Slices were continuously superfused with oxygenated $\left(95 \% \mathrm{O}_{2} / 5 \% \mathrm{CO}_{2}\right.$ ) aCSF composed of the following (in $\mathrm{mm}): 130 \mathrm{NaCl}, 3 \mathrm{KCl}, 1.25 \mathrm{NaH}_{2} \mathrm{PO}_{4}, 26 \mathrm{NaHCO}_{3}, 10$ glucose, $1 \mathrm{MgCl}_{2}$, $2 \mathrm{CaCl}_{2}$, and maintained at $34^{\circ} \mathrm{C}$. Slices were imaged on an Olympus Fluoview 1000 Laser Scanning Confocal Microscope equipped with a $40 \times$ UPlanApo objective $(\mathrm{NA}=1.3)$. Slices were allowed to equilibrate in the imaging chamber for $10 \mathrm{~min}$ before initiating recording. Cells expressing EGFP or mCherry were identified using epifluorescence and were imaged using the 488 and 546 laser lines, respectively. Previously, we showed that the minimal GFAP promoter $\left(\mathrm{GFA}_{\mathrm{ABC1D}}\right)$ limits trans- duction to astrocytes (Jackson et al., 2014). To control for possible variability between different sets of cultures, all experiments included control and experimental slices from the same cultures and were imaged randomly interspersed throughout the same day. Slices were visually inspected to ensure that the slice was intact and that the hippocampus retained its laminar organization. Cells were visually selected based on their complex morphology, and lack of a reactive phenotype (nonhypertrophic). Cells at the surface of the slice or at the slice margins were excluded. For all cells, image stacks (15-25 optical sections; $1 \mu \mathrm{m}$ $z$-spacing) were acquired to aid in retrospective identification. A subfield of these astrocytes was identified and imaged at $512 \times 512$ pixels with an additional $4-5 \times$ digital zoom. For imaging mitochondrial movement, image stacks (3-10 optical sections; $1 \mu \mathrm{m} z$-spacing) were collected every $6-10 \mathrm{~s}$ for $15 \mathrm{~min}$ from a field containing $5-20$ astrocyte processes and at least 10 mitochondria. For GCaMP imaging, a single optical section was imaged at a frequency of $1 \mathrm{~Hz}$. Care was taken to choose processes or groups of processes that existed in a single optical section. Pharmacological agents were administered via superfusion using a solution changer (VC-6; Warner Instruments).

Image analysis. All data analyses were performed blinded to transfection or treatment conditions. All data analyses were conducted using the FIJI implementation of the NIH ImageJ program (http://rsb.info.nih. gov/ij/) (Schneider et al., 2012). All images were background corrected. Motion artifacts due to slice drift were corrected using the MultistackReg plugin of FIJI to implement rigid registration, aligning all images in a time-lapse series to the original image. As GCaMP5G and GCaMP6S have low fluorescence at basal $\left[\mathrm{Ca}^{2+}\right]_{\mathrm{i}}$, image series from the simultaneously acquired mCherry fluorescence were first aligned and this alignment file used to align the GCaMP image series.

To track the mobility of individual mitochondria, image stacks (3-5 image planes; $1 \mu \mathrm{m}$ spacing) were compressed into a single plane (maximal $z$-compression). Individual mitochondria were tracked using the MTrackJ plugin to ImageJ (Meijering et al., 2012). A mitochondrion was considered mobile if its displacement exceeded $2 \mu \mathrm{m}$ during the $15 \mathrm{~min}$ imaging epoch. Kymographs (displacement vs time) were constructed from individual astrocyte processes for display purposes and are displayed such that time is on the $y$-axis. Mitochondria that are not mobile appear as vertical lines, whereas mobile mitochondria appear as diagonal lines across the kymograph.

To analyze GCaMP fluorescence, kymographs were constructed by tracing each process, guided by the mCherrry fluorescence images. $\mathrm{Ca}^{2+}$ signaling events were selected based on a threshold of $3 \times$ the SD of the mean, similar to what has been used to isolate $\mathrm{Ca}^{2+}$ sparks from cardiac myocytes (Cheng et al., 1999), and exported as text files for further analysis. Examples of these kymographs are presented in Figure 2B, $C$ and are oriented with time progressing toward the right.

Statistics and data analysis. All data are representative of at least three independent sets of experiments (separate sets of slices prepared on separate days). Analysis was conducted blinded to treatment. Time constants (tau) were calculated using ClampFit9 (Molecular Devices). The decay phase of the $\mathrm{Ca}^{2+}$ transient was consistent with a first-order exponential decay process $\left(R^{2}>0.7\right)$. The results of fits where $R^{2}$ was $<0.7$ were discarded. $\mathrm{Ca}^{2+}$ traces were produced using Microcal Origin (OriginLab). Normality of data distribution was assessed using the D'Agostino and Pearson omnibus normality test. Normally distributed data were assessed using Student's $t$ test or ANOVA with Bonferroni's multiple comparisons, as appropriate. Non-normally distributed data were assessed via Mann-Whitney test or Friedman's test with multiple comparisons as appropriate and are expressed as median with interquartile range (IQR). Statistical significance between cumulative probability distributions was assessed using the Kolmogorov-Smirnov test. Statistical significance of linear regressions was assessed using Pearson's coefficient of variance. All statistical analyses were conducted using Graphpad Prism software.

\section{Results}

We recently showed that inhibition of neuronal activity (TTX), glutamate uptake (TFB-TBOA), or reversed $\mathrm{Na}^{+} / \mathrm{Ca}^{2+}$ exchange (KB-7943 or YM-244769) increases the percentage of 
A
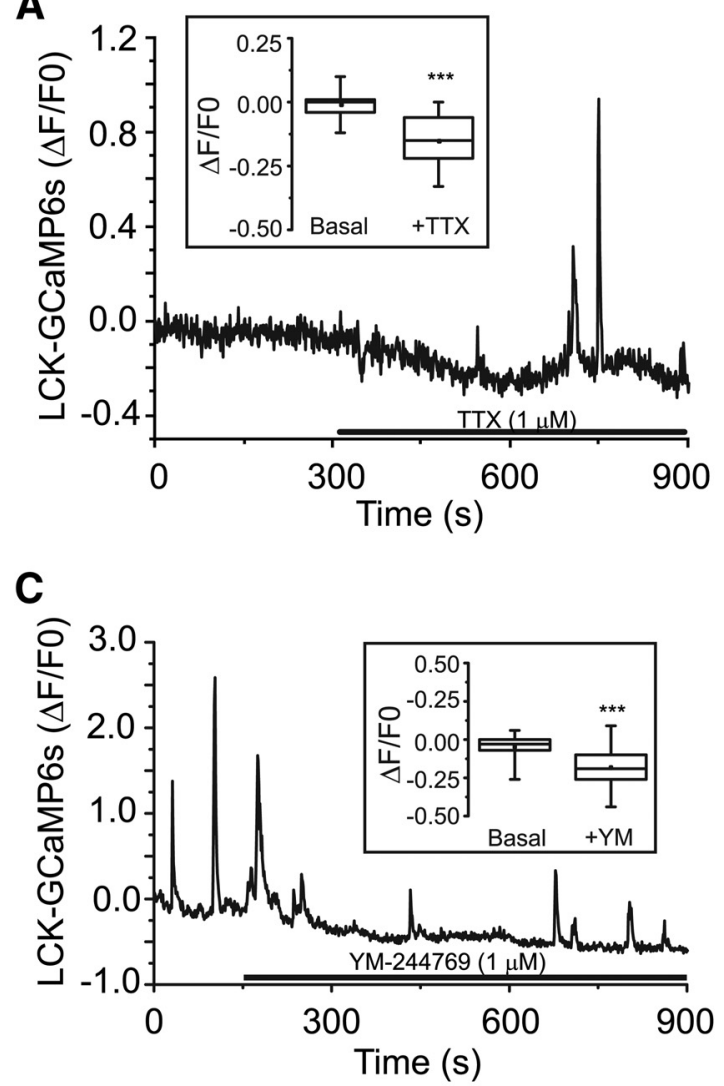
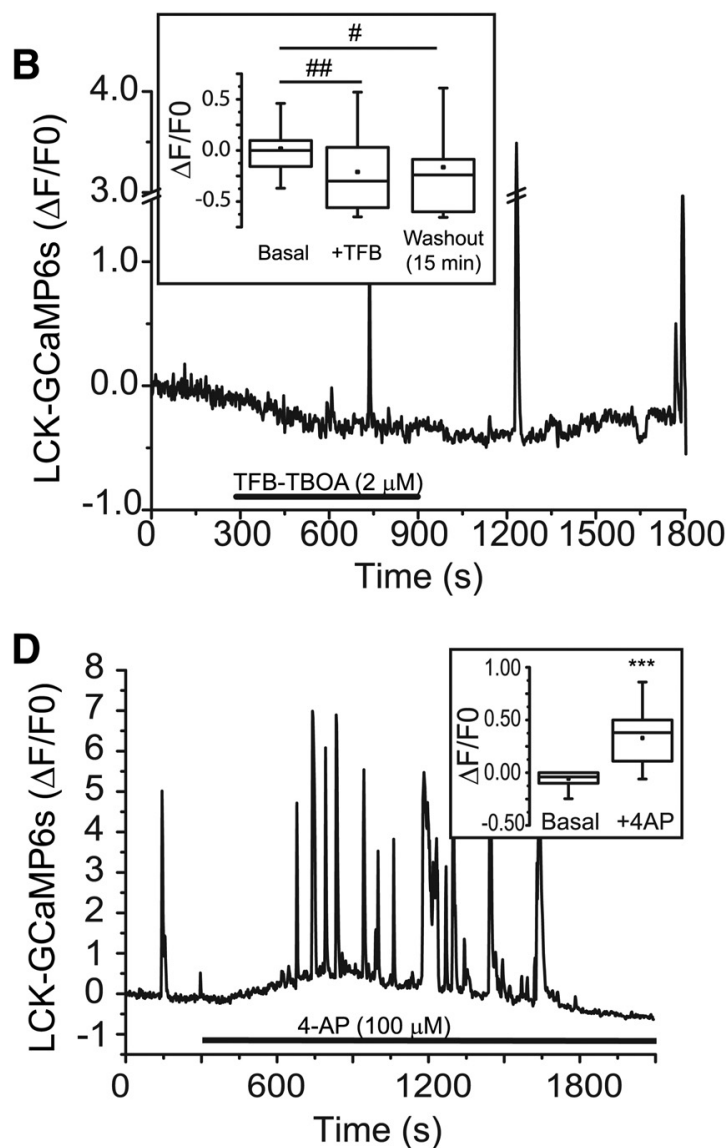

Figure 1. Pharmacological agents that increase the percentage of mobile mitochondria also decrease basal $\left[\mathrm{Ca}^{2+}\right]_{\mathrm{i}}$. Astrocytes in organotypic cultures were transfected with a membranetargeted-mCherry fluorescent protein driven by a GFAP promoter (GFA ${ }_{A B C 1 D}-m$ Cherry) and the high affinity genetic $\mathrm{Ca}^{2+}$ indictor LCK-GCaMP6s. Representative traces derived from single astrocyte processes depict changes in $\left[\mathrm{Ca}^{2+}\right]_{\mathrm{i}}$ following application of TTX ( $\boldsymbol{A}, 1 \mu \mathrm{m} ; n=45$ processes, 8 cells), TFB-TBOA ( $\boldsymbol{B}, 2 \mu \mathrm{m} ; n=27$ processes, 6 cells), YM- 244769 ( $\boldsymbol{C}, 1 \mu \mathrm{m} ; n=45$ processes, 10 cells), or 4-AP (D, $100 \mu \mathrm{m} ; n=26$ processes, 6 cells). Slices were continuously superfused with oxygenated-aCSF and treatments applied by superfusion as indicated by application bars. Box-and-whisker plots (inset) represent basal GCaMP6s fluorescence before and after treatment with the indicated agents. Individual values are plotted within each box. Error bars indicate $5 \%-95 \%$ range. Shoulders of boxes indicate $25 \%-75 \%$ intervals. Median of data is highlighted by horizontal line. Mean is indicated by a circle. ${ }^{* * *} p<0.0001$ (Wilcoxon matched-pairs signed rank test). ${ }^{\#} p<0.05$ (Friedman test with multiple comparisons). ${ }^{\#} p<0.001$ (Friedman test with multiple comparisons).

mobile mitochondria in astrocyte processes. Inhibition of neuronal activity with TTX decreases the probability that mitochondria appose glutamate transporters in astrocytes without changing the proximity of glutamate transporters (GLT-1) to synapses (VGLUT1) (Jackson et al., 2014). Ugbode et al. (2014) also recently showed that neurons/neuronal activity increase colocalization of mitochondria with GLT1 in astrocyte-neuron cocultures. In neurons and other systems (Saotome et al., 2008; Macaskill et al., 2009), the arrest of mitochondria at domains of elevated activity proceeds, in part, through elevations of intracellular calcium $\left(\left[\mathrm{Ca}^{2+}\right]_{\mathrm{i}}\right)$. Based on these sets of observations, we decided to explore a role for $\mathrm{Ca}^{2+}$ signaling in regulating the arrest of mitochondria in astrocyte processes.

Treatments that increase mitochondrial mobility decrease basal $\left[\mathrm{Ca}^{2+}\right]_{\mathbf{i}}$

We used organotypic hippocampal cultures derived from P8-P12 rats to examine $\mathrm{Ca}^{2+}$ signaling in the processes of individual astrocytes. In contrast to primary cultures of astrocytes, astrocytes in organotypic culture maintain their fine architecture and express a complement of proteins more representative of that found in vivo (Benediktsson et al., 2005; Genda et al., 2011; Jackson et al., 2014). We predicted that treatments that increase mitochondrial mobility would decrease basal $\left[\mathrm{Ca}^{2+}\right]_{\mathrm{i}}$. To examine changes in basal $\left[\mathrm{Ca}^{2+}\right]_{\mathrm{i}}$, astrocytes were transduced with the genetic $\mathrm{Ca}^{2+}$ indicator, GCaMP6S. This indicator was chosen because of its relatively higher affinity $\left(\right.$ lower $\mathrm{K}_{\mathrm{d}}$ ) for $\mathrm{Ca}^{2+}(144$ $\mathrm{nM}$ ) (Chen et al., 2013), which is closer to astrocytic basal $\left[\mathrm{Ca}^{2+}\right]_{\mathrm{i}}$ (50-250 nM) (Fatatis and Russell, 1992; Reyes et al., 2012), and therefore is more sensitive to changes in this range. As others have done, we fused GCaMP6s to the membrane-tethering domain of the lymphocyte-specific protein tyrosine kinase (LCK) to allow movement of the indicator out into the small processes of the astrocyte (Benediktsson et al., 2005; Shigetomi et al., 2010b). Astrocytes were cotransfected with a membrane-targeted mCherry driven by a minimal GFAP promoter to visualize the astrocyte processes and to aid in image registration. Individual nonreactive astrocytes were identified, and subfields containing 7-15 processes were imaged for $15 \mathrm{~min}$. Blockade of neuronal activity with TTX (Fig. 1A), glutamate uptake with TFB-TBOA (Fig. 1B), or reversed $\mathrm{Na}^{+} / \mathrm{Ca}^{2+}$-exchange with YM-244769 (Fig. 1C) all decreased basal $\left[\mathrm{Ca}^{2+}\right]_{\mathrm{i}}$. These effects were relatively rapid, occurring within $\sim 60 \mathrm{~s}$ (Fig. $1 A-C$ ). The decrease in $\left[\mathrm{Ca}^{2+}\right]$ observed with TFB-TBOA only partially recovered following washout, consistent with the high affinity and slow washout observed when this inhibitor was first described (Shimamoto et al., 2004). Increasing neuronal activity with 4-aminopyridine (4-AP; $100 \mu \mathrm{M})$ increased basal $\left[\mathrm{Ca}^{2+}\right]$ (Fig. $\left.1 D\right)$. The simplest explanation of 

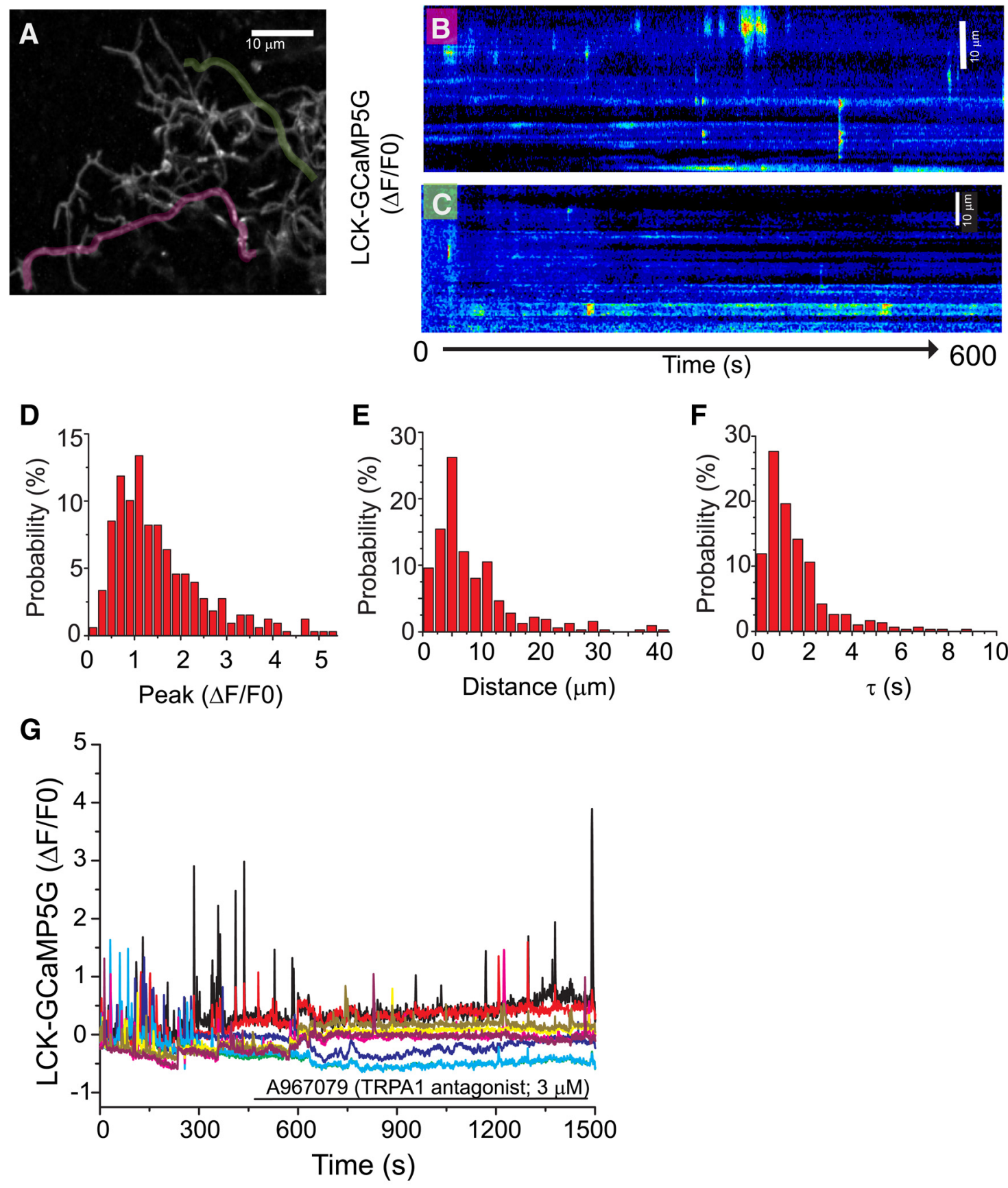

Figure 2. Characterization of $\mathrm{Ca}^{2+}$ signaling events in astrocyte processes in organotypic cultures of rat hippocampus. Astrocytes in organotypic cultures of rat hippocampus were transfected

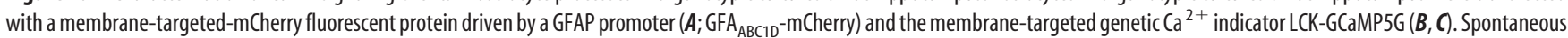
$\mathrm{Ca}^{2+}$ increases were recorded over a 10 min imaging window. Individual processes $(\boldsymbol{B}, \boldsymbol{C})$ from the astrocyte depicted in $\boldsymbol{A}$ (red and green overlays) were traced and kymographs created from the time-series. $\left[\mathrm{Ca}^{2+}\right]_{\mathrm{i}}$ increases are depicted using a pseudo-color lookup table. Individual $\mathrm{Ca}^{2+}$ transients were analyzed for amplitude $(\boldsymbol{D} ;$ peak $\Delta \mathrm{F} / \mathrm{F} 0)$, distance propagated $(\boldsymbol{E} ; \mu \mathrm{m})$, and tau $(\boldsymbol{F}$, seconds) and the results depicted as histographs ( $n=742$ spikes, 111 processes, 15 cells). $\mathbf{G}$, Representative trace depicts LCK-GCaMP5G fluorescence changes from multiple processes of the same astrocyte treated with the TRPA1 antagonist (A967079, $n=3$ cells, 16 processes).

these and our recently published data (Jackson et al., 2014) is that neuronal activity followed by astrocytic glutamate uptake and subsequent reversed operation of the $\mathrm{Na}^{+} / \mathrm{Ca}^{2+}$-exchanger results in increased $\mathrm{Ca}^{2+}$ in astrocytic processes. A similar effect of glutamate uptake on intracellular $\left[\mathrm{Ca}^{2+}\right]$ has been observed in astrocyte cultures (Reyes et al., 2012; Magi et al., 2013). Because of variability in the latency to peak and duration of the $\left[\mathrm{Ca}^{2+}\right]$ increase observed with 4-AP (Fig. 1D), we were not able to test whether this increase was reversed by application of TFB-TBOA or YM-244769.

Properties of spontaneous $\mathrm{Ca}^{2+}$ signals in astrocyte processes Astrocytes exhibit increases in $\left[\mathrm{Ca}^{2+}\right]$ both spontaneously and in response to evoked stimuli (synaptic activation, glutamate, etc) (Cornell-Bell et al., 1990; Fatatis and Russell, 1992; Nett et al., 2002). These events have been characterized in the soma and 
primary processes of astrocytes in cultures, in acute and cultured brain slices, and in vivo (Bernardinelli et al., 2011; Pérez-Alvarez et al., 2013). Newer methodologies using targeted genetic $\mathrm{Ca}^{2+}$ sensors (GCaMPs) have revealed more localized $\mathrm{Ca}^{2+}$ signals within the smaller secondary and tertiary astrocyte processes (Shigetomi et al., 2010b, 2012, 2013a). These local events have not been characterized in organotypic cultures. Therefore, we first examined the properties of spontaneous $\left[\mathrm{Ca}^{2+}\right]_{\mathrm{i}}$ spikes using the genetic $\mathrm{Ca}^{2+}$ indicator LCK-GCaMP5G. This indicator was chosen both for its lower affinity $\left(\mathrm{K}_{\mathrm{d}}=440 \mathrm{nM}\right)$ and its relatively faster $\mathrm{K}_{\text {off }}\left(2.52 \mathrm{~s}^{-1}\right)$ relative to GCaMP6s $\left(\mathrm{Kd}=144 \mathrm{~nm}\right.$; Koff $\left.=1.12 \mathrm{~s}^{-1}\right)$ (Chen et al., 2013). Individual processes were traced using mCherry fluorescence (Fig. 2A, magenta and green lines), and kymographs were constructed to identify $\mathrm{Ca}^{2+}$ signals within individual processes (Fig. 2B,C). As observed in other systems (Shigetomi et al., 2010a, 2012), astrocytes exhibit small (Fig. 2D; median peak $\Delta \mathrm{F} /$ F0 = 1.2, IQR: 0.8, 2.0), brief (Fig. $2 F$; median tau $=1.3 \mathrm{~s}$, IQR: $0.7,2.0)$, or a $t_{1 / 2}$ of $\sim 0.8 \mathrm{~s}$ increases in $\left[\mathrm{Ca}^{2+}\right]$ that are spatially discrete (Fig. 2E; median distance propagated $=5.7 \mu \mathrm{m}$, IQR: $3.8,11.3 ; n=15$ cells, 111 processes, 742 events). These $\left[\mathrm{Ca}^{2+}\right]_{i}$ transients appear in $36 \%$ of processes and are not coordinated between processes (Fig. $2 \mathrm{~B}, \mathrm{C} ; n=251$ processes, 23 cells). In the $36 \%$ of processes that exhibited $\mathrm{Ca}^{2+}$ transients, oscillations appeared with a mean frequency of $0.18 \pm 0.03$ spikes $/ \mathrm{min} /$ process (mean \pm SEM of 90 processes), indicating a high degree of variability even between processes. As has been previously observed in other systems (Shigetomi et al., 2010b), application of the TRPA1 antagonist (A967079; $3 \mu \mathrm{M}$ ) decreased both the frequency (to $12 \pm 4 \%$ of control, $p<0.0001$ ) and amplitude (to $45 \pm 7 \%$ of control; $p<0.0001, n=16$ processes; 3 cells) of these transients (Fig. 2G). As this is a concentration that would be expected to inhibit $90 \%$ of TRPA1 channel activity $\left(\mathrm{IC}_{50}=289\right.$ nM) (Chen et al., 2011), this suggests the presence of other processes coupled to increases in $\left[\mathrm{Ca}^{2+}\right]_{\mathrm{i}}$ and is consistent with observations of $\mathrm{Ca}^{2+}$ signaling in both acute slice and primary cultures of astrocytes (Shigetomi et al., 2010b; Haustein et al., 2014; for review, see Rusakov et al., 2014).

From these analyses, it also became apparent that these $\mathrm{Ca}^{2+}$ spikes frequently occur in the same spatially restricted location within a process (Fig. $2 B, C$ ). We hypothesized that mitochondria might accumulate at these sites. To test this, we transfected astrocytes with plasmids encoding LCK-GCaMP5G and the mitochondrially targeted DsRed2 driven by the minimal GFAP promoter ( $\mathrm{pGFA}_{\mathrm{ABC1D}}$ :DsRed2-mito). As was observed in analyses presented in Figure 2, time-lapse microscopy reveals domains of repeated $\mathrm{Ca}^{2+}$ signaling (Fig. $3 B$ ) that overlap with mitochondria (Fig. $3 A, C$ ). Indeed, $98.3 \pm 3 \%$ of $\mathrm{Ca}^{2+}$ transients overlapped at least 1 mitochondria, whereas $62 \pm 6 \%$ of mitochondria encountered a $\mathrm{Ca}^{2+}$ transient during a 10 min imaging window ( $n=9$ cells; 32 processes). To further examine the relationship of mitochondria to these $\mathrm{Ca}^{2+}$ spikes, we measured the length of each process and the sum of the lengths of mitochondria in each process. These data were expressed as the percentage of the process occupied by mitochondria (\% Mito occupancy). We found that the frequency (Fig. 3D) and the lateral spread of indi- vidual transients (Fig. $3 E$ ) is inversely proportional to the percentage of the process occupied by mitochondria. Given the known relationship of mitochondrial recruitment to sites of high $\mathrm{Ca}^{2+}$, it seems likely that mitochondria are being recruited to locations with high TRPA1 channel activity, but one cannot rule out the possibility that TRPA1 channels are selectively trafficked to processes with more mitochondria.

\section{Effect of agents that increase mitochondrial mobility on spontaneous $\mathrm{Ca}^{2+}$ signals in astrocyte processes}

Mitochondria accumulate at sites of elevated $\mathrm{Ca}^{2+}$ in neurons and other cells (Li et al., 2004; Macaskill et al., 2009; Wang and Schwarz, 2009). The proper positioning of mitochondria at these domains controls $\mathrm{Ca}^{2+}$ signaling (Csordás et al., 1999; Wang et al., 2003; for review, see Rizzuto et al., 2012). Although TTX, TFB-TBOA, and YM-244769 decrease basal $\left[\mathrm{Ca}^{2+}\right]_{\mathrm{i}}$, they also increase the percentage of mitochondria that are mobile (Jackson et al., 2014). We hypothesized that the increased movement of mitochondria by these agents might increase $\mathrm{Ca}^{2+}$ signaling in astrocytic processes. Astrocytes were transfected with LCKGCaMP5G and membrane-targeted mCherry. Images were collected for $10 \mathrm{~min}$ before superfusion of pharmacological agents (vehicle/aCSF, TTX, TFB-TBOA, YM-244769) to measure baseline $\mathrm{Ca}^{2+}$ signaling and then for an additional $15 \mathrm{~min}$. The properties of the $\mathrm{Ca}^{2+}$ signals measured in the final $10 \mathrm{~min}$ of drug treatment were compared with baseline. As was previously observed (Dwight Bergles, personal communication), the frequency of these $\mathrm{Ca}^{2+}$ spikes increases with time even in slices continuously perfused with aCSF (vehicle) from $0.28 \pm 0.05$ to $0.49 \pm$ 0.07 spikes $/ \mathrm{min} /$ process $(n=97$ processes; $p<0.0001$, paired Student's $t$ test). Superfusion with aCSF was not accompanied by a change in the peak amplitude, rate of decay (tau), or spread of the $\mathrm{Ca}^{2+}$ signal (11 cells; 83 processes, 743 events; data not shown). TTX ( $1 \mu \mathrm{M}$; Fig. $4 A$ ) prolonged the half-life (tau, $p<$ 0.001 , Kolmorogov-Smirnov test) but did not alter amplitude or the spatial spread of these signals. Although there was an increase in the frequency of oscillations, it was not significantly different from that observed with vehicle ( $p=0.4, n=74$, Kruskal-Wallis test with Dunn's multiple comparisons test). TFB-TBOA $(3 \mu \mathrm{M})$ increased the amplitude $(\Delta \mathrm{F} / \mathrm{F} 0)$ of the $\mathrm{Ca}^{2+}$ transients (from $1.0 \pm 0.1$ to $1.5 \pm 0.1, p<0.0001$, Kolmorogov-Smirnov test) without affecting half-life or spatial spread. TFB-TBOA increased 
A
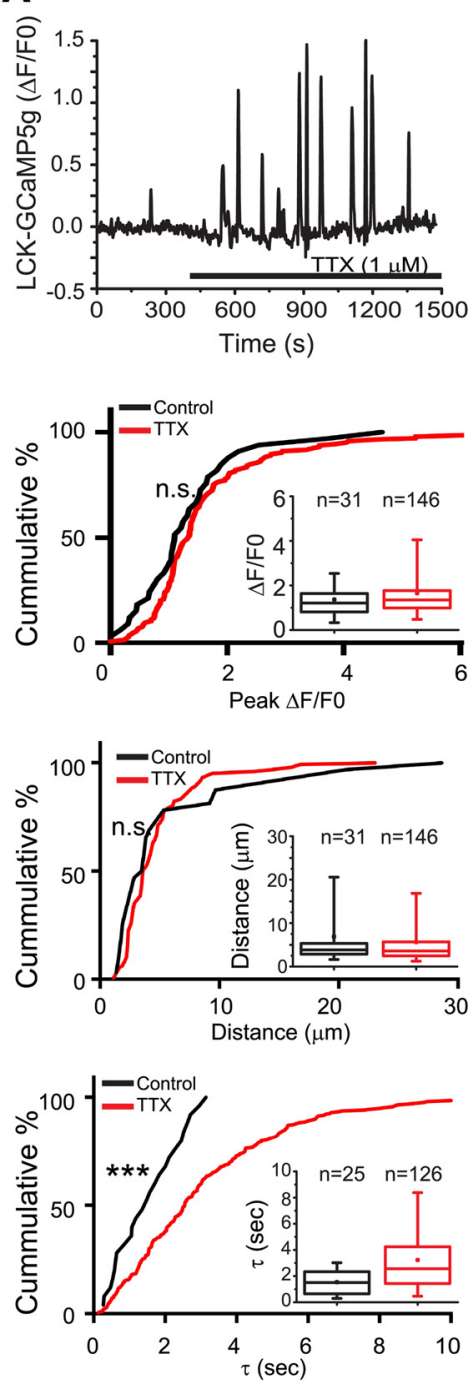

B
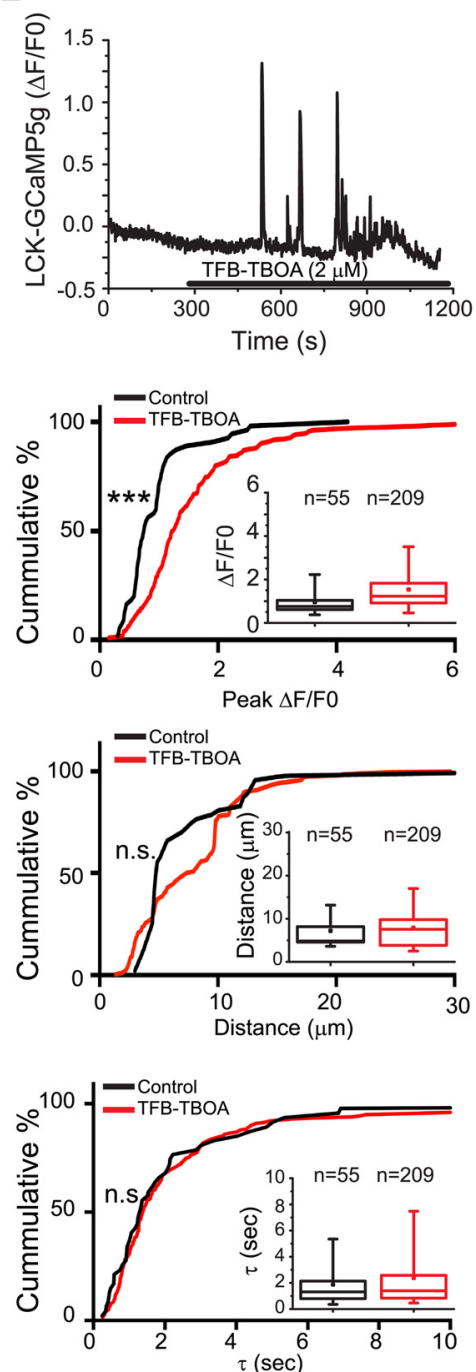

C
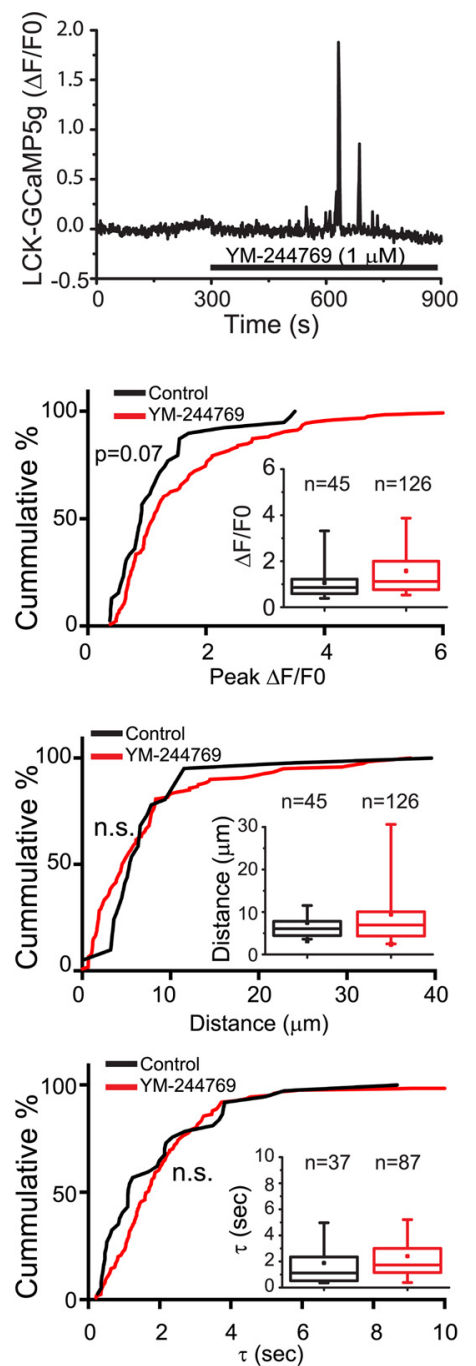

Figure 4. Effect of pharmacologic agents on the characteristics of spontaneous $\mathrm{Ca}^{2+}$ oscillations in astrocyte processes. Astrocytes in organotypic cultures of rat hippocampus were transfected with a membrane-targeted mCherry fluorescent protein driven by a GFAP promoter (GFA ${ }_{A B C 1 D}$ :mCherry) and the genetic Ca ${ }^{2+}$ indicator LCK-GCaMP5G. Slices were continuously superfused with oxygenated-aCSF and treatments applied by superfusion of TTX ( $\boldsymbol{A} ; 1 \mu \mathrm{M})$, TFB-TBOA ( $\boldsymbol{B} ; 2 \mu \mathrm{M})$, or YM-244769 (C; $1 \mu \mathrm{M})$ as indicated by application bars. The distance traveled ( $\mu \mathrm{m})$, time constants (seconds), and amplitudes (peak $\Delta \mathrm{F} / \mathrm{F} 0$ ), of the individual $\mathrm{Ca}^{2+}$ transients were quantified before (black) and after application of the indicated agents (red), and the results are depicted as both cumulative probability distributions and box-and-whisker plots (inset). Error bars indicate $5 \%-95 \%$ range. Shoulders of boxes indicate $25 \%-75 \%$ intervals. Median of data is highlighted by horizontal line. ${ }^{* * *} p<0.0001$ (Kolmorogov-Smirnov test). n.S., Not significant.

the frequency of these $\mathrm{Ca}^{2+}$ spikes twofold relative to that observed in vehicle-treated slices $(p<0.0001, p=34$ processes, Kruskal-Wallis test with Dunn's multiple comparisons test). Inhibition of reversed $\mathrm{Na}^{+} / \mathrm{Ca}^{2+}$-exchange with YM-244769 (1 $\mu \mathrm{M}$ ) had a nearly significant effect on amplitude (from $1.1 \pm 0.1$ to $1.6 \pm 0.1, p=0.07$ ), but did not alter tau, or spatial spread. The effect of YM-244769 on frequency was not different from that observed with vehicle ( $p=0.6, n=49$ processes, Kruskal-Wallis test with Dunn's multiple comparison's test). Together, these data are consistent with the notion that increasing mitochondrial mobility with pharmacologic inhibitors increases $\mathrm{Ca}^{2+}$ signaling, but these agents do not only change mitochondrial mobility. For example, inhibition of glutamate transporters can increase ambient glutamate (Isaacson and Nicoll, 1993; Jabaudon et al., 1999) with consequent activation of glutamate receptors (Huang et al., 2004; Haustein et al., 2014). The increased frequency and amplitude of $\mathrm{Ca}^{2+}$ transients in the presence of TFB-TBOA are consistent with this (Fig. 4B). Interestingly, previous experiments failed to show an effect of either activating or inhibiting mGluR5 on the percentage of mobile mitochondria (Jackson et al., 2014). Prolonged exposure to elevated glutamate, however, may result in desensitization of neuronal glutamate receptors (Trussell et al., 1988). Therefore, it is important to use other strategies that directly affect mitochondrial positioning or function.

\section{Miro 1 and Miro2 colocalize with and regulate mobility of astrocytic mitochondria}

In our previous study, we showed that disruption of microtubule assembly with vinblastine or disruption of actin assembly with cytochalasin D reduced mitochondrial mobility in astrocytic processes, implying a role for motor proteins in their movement (Jackson et al., 2014). Miro1 and Miro2 localize to mitochondria and mediate both the movement of mitochondria and their $\mathrm{Ca}^{2+}$-sensitive immobilization by a mechanism that is still controversial but somehow involves disengagement of mitochondria 
from the cytoskeleton (Fransson et al., 2003, 2006; Saotome et al., 2008; Macaskill et al., 2009; Wang and Schwarz, 2009).

Given that the Miro proteins mediate the arrest and accumulation of mitochondria at sites of high activity in neurons, we asked whether either of the Miro isoforms were present within astrocytes and whether they regulate mitochondrial mobility in astrocytes. mRNA for both Miro1 and Miro2 is present in astrocytes. Indeed, expression arrays and RNAseq data suggest that both Miro1 and Miro2 are as abundant or slightly enriched in astrocytes relative to neurons (Cahoy et al., 2008; Zhang et al., 2014). To assess the presence and distribution of Miro protein in astrocytes, we used both organotypic cultures of rat hippocampus and primary cultures of cortical astrocytes. Astrocytes in slice culture were transfected with a membrane-targeted mCherry driven by a minimal GFAP promoter $\left(\mathrm{GFA}_{\mathrm{ABC} \mathrm{D}}\right.$; Fig. $5 A, E)$ and an EGFP targeted to the mitochondrial matrix (EGFP-mito; Fig. 5C,G). Slices were subsequently fixed and immunostained with antibodies targeted against Miro1 (Fig. 5B) or Miro2 (Fig. $5 F$ ). Punctate Mirol and Miro2 immunofluorescence colocalizes with EGFP-mito fluorescence within astrocyte processes, with several puncta evident per mitochondrion (Fig. 5D,H). This punctate pattern of expression has been described previously in yeast with the Miro homolog Gem1 (Kornmann et al., 2011). We also tested for expression of Miro1 and Miro2 in primary cultures of rat astrocytes and rat cortical tissue. Immunoblots revealed the presence of bands at the appropriate $(\sim 70$ $\mathrm{kDa}$ ) size (Fig. 5I and Fig. 5J, respectively). However, we note the presence of additional bands at $\sim 100 \mathrm{kDa}$ (particularly prominent with Miro2; Fig. 5J). Ubiquitinated Miro appears as an $\sim 100 \mathrm{kDa}$ protein via immunoblot (Birsa et al., 2014), suggesting ubiquitination of Miro (particularly Miro2) protein in primary cultures of astrocytes.

We transfected astrocytes with plasmids encoding EGFPmito, EGFP-Miro1, EGFP-Miro2, or $\mathrm{Ca}^{2+}$-insensitive mutants of Miro1 or Miro2 (termed Miro ${ }^{\mathrm{KK}}$ ) in which the $\mathrm{Ca}^{2+}$ coordinating EF-hand motifs are mutated (E208K/E328K) (Fransson et al., 2006). Astrocytes were cotransfected with membrane-targeted mCherry driven by a minimal GFAP promoter $\left(\mathrm{GFA}_{\mathrm{ABC1D}}\right)$ to aid in the identification of astrocytes. Discrete, EGFP-expressing mitochondria were readily identifiable within the astrocyte processes (Fig. 6A-E). Mitochondrial movement was followed over a 15 min period using confocal microscopy in fields containing at least $3-5$ astrocyte processes and at least 10 mitochondria. The percentage of mobile mitochondria (defined as $>2 \mu \mathrm{m}$ movement in $15 \mathrm{~min}$ ), the total distance mobile mitochondria move in $15 \mathrm{~min}$, the maximum instantaneous velocity, and average mitochondrial length were examined. As we have previously observed, the majority of mitochondria were stationary $(20.9 \pm 3.2 \%$ mobile $)$ under control conditions (EGFP-mito transfected). Consistent with the
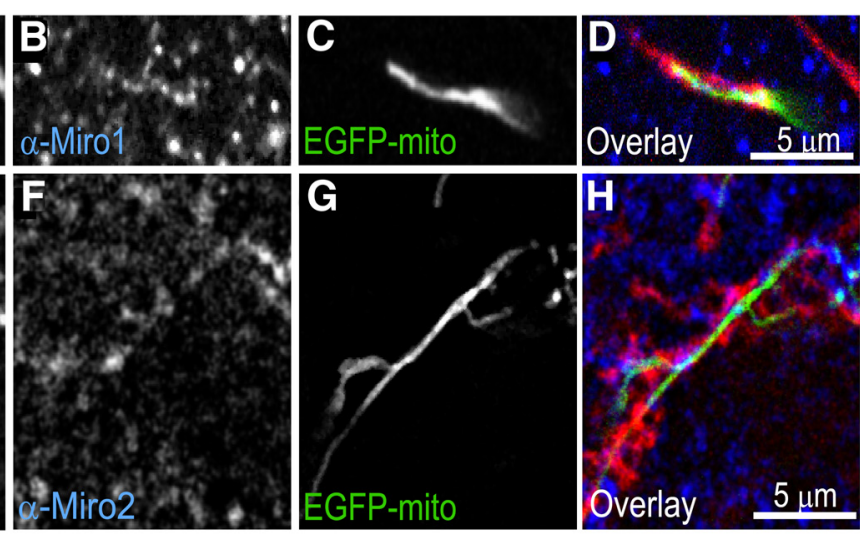

J 150

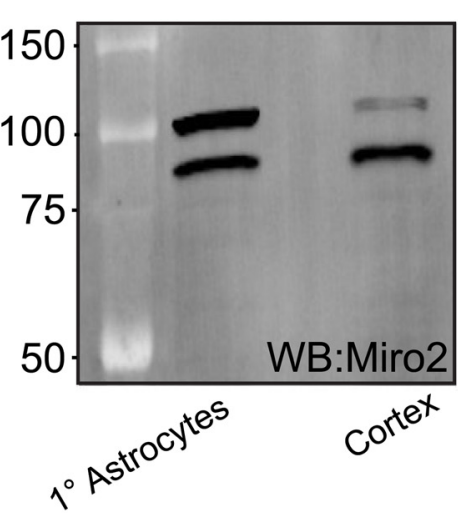

WB:Miro1 $\quad 50$

Figure 5. Expression and colocalization of Miro proteins with mitochondria in astrocytes. Representative images of astrocyte processes in slice culture transfected with the CDNA encoding a membrane-targeted-mCherry fluorescent protein driven by the

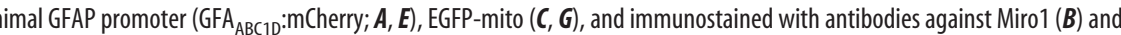
merged $(\boldsymbol{D}, \boldsymbol{H})$ demonstrate that transfected cells express Miro1 and Miro2 and that these proteins colocalize with mitochondria. Scale bar, $5 \mu \mathrm{m}$. $I, J$, Representative immunoblots of tissue derived from primary cultures of rat cortical astrocytes

pattern of endogenous Miro expression presented in Figure 5, EGFP-Miro1 or EGFP-Miro2 expression colocalized with DsRed2-mito expression in the astrocyte processes (data not shown) and appeared as discrete vermiform structures consistent with a mitochondrial localization. Exogenous expression of EGFP-Miro1 had no significant effect on the percentage of mobile mitochondria on any of the parameters measured (Fig. $6 F-I)$. In contrast, exogenous expression of EGFP-Miro2 doubled the percentage of mobile mitochondria (Fig. $6 D, F$ ), suggesting that endogenous Miro protein expression might limit mitochondrial mobility. Expression of $\mathrm{Ca}^{2+}$-insensitive mutants of either Miro1 (Fig. 6C,F; EGFP-Miro1 ${ }^{\mathrm{KK}}$ ) or Miro2 (Fig. 6E, F; EGFP-Miro2 ${ }^{\mathrm{KK}}$ ) approximately doubled the percentage of mobile mitochondria relative to control. EGFP-Miro $1^{\mathrm{KK}}$ and EGFP-Miro ${ }^{\mathrm{KK}}$ had small but significant effects on some of the other measures, but the biological relevance of these effects would be difficult to determine given the small effect sizes (Fig. 6F-I). The effects on mitochondrial length are consistent with previous publications (Frederick et al., 2004; Fransson et al., 2006; Glater et al., 2006; Saotome et al., 2008).

Given that the exogenous expression of EGFP-Miro ${ }^{\mathrm{KK}}$ increases the percentage of mobile mitochondria within astrocytic processes, this provides a tool to more specifically disrupt mitochondrial positioning within astrocytes. We hypothesized that the $\mathrm{Ca}^{2+}$-dependent and Miro-dependent positioning of mitochondria might influence the properties of the $\mathrm{Ca}^{2+}$ spikes observed in astrocytic processes. Astrocytes in slice culture were transfected with LCK-GCaMP5G, membrane-targeted mCherry, and either Mirol ${ }^{\mathrm{KK}}$-myc or myc vector (control). We monitored 

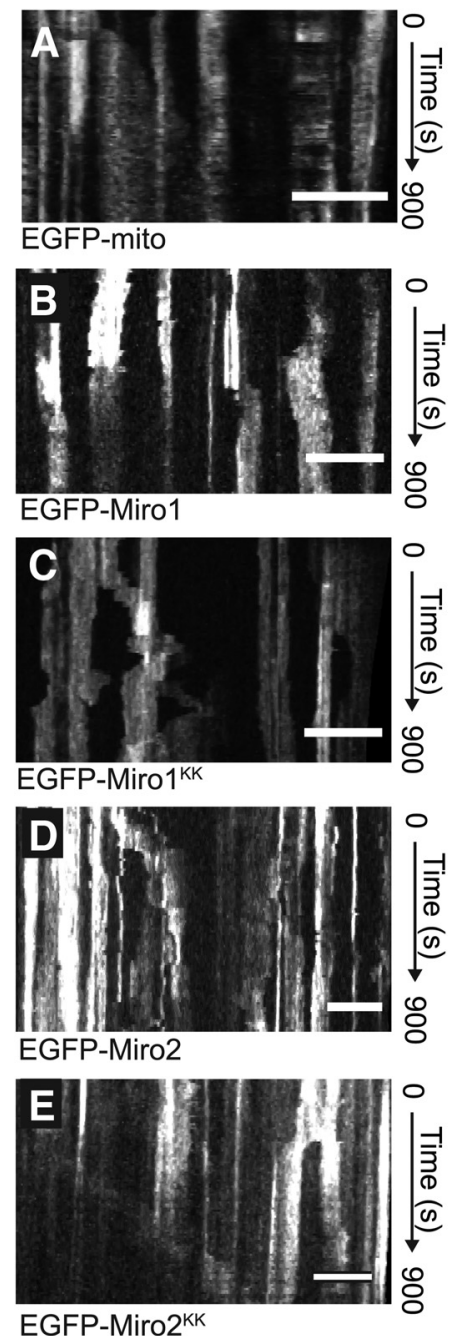
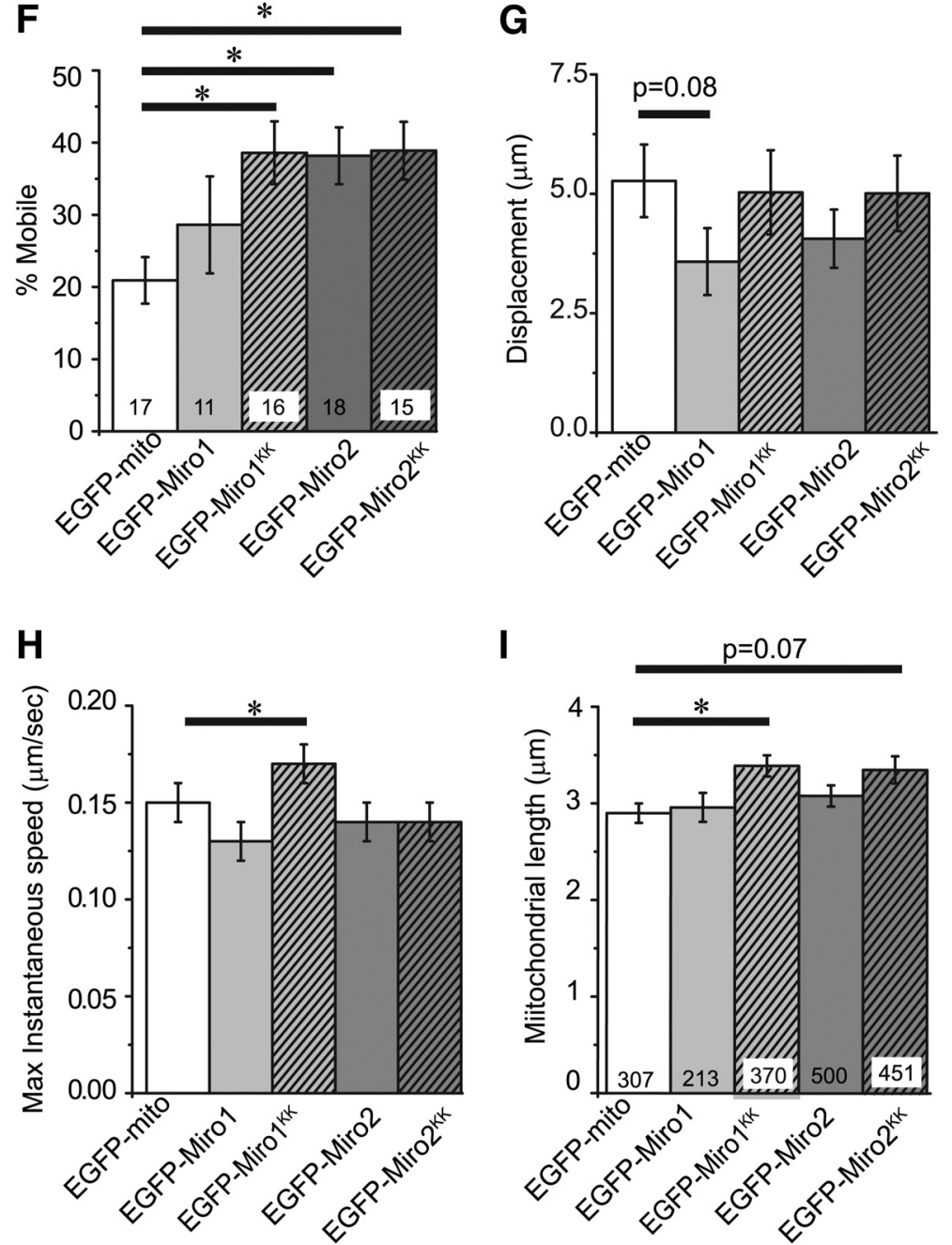

Figure 6. Miro proteins regulate mitochondrial movement in astrocyte processes. Astrocytes were transfected with plasmids encoding a membrane-targeted-mCherry fluorescent protein driven by the minimal GFAP promoter (GFA ${ }_{\mathrm{ABC} 1 \mathrm{D} \text { : }}$ Cherry) and (A) EGFP-mito, $(\boldsymbol{B})$ EGFP-Miro1, (C) EGFP-Miro ${ }^{\mathrm{KK}},(\boldsymbol{D})$ EGFP-Miro2, or (E) EGFP-Miro2 ${ }^{\mathrm{KK}}$. The movement of labeled mitochondria was tracked in subfields of astrocyte processes. Kymographic representations depict the movement of mitochondria in these processes over a 15 min imaging epoch (time increases down page). Stationary mitochondria are seen as straight lines and moving mitochondria as diagonal lines. Scale bar, $10 \mu \mathrm{m}$. $\boldsymbol{F}$, Bar chart represents the percentage of mitochondria that were mobile during the imaging epoch, normalized to the total number of mitochondria that were visualized during that period. Results are mean \pm SEM. $G$, Bar chart represents the average displacement of individual mobile mitochondria. $\boldsymbol{H}$, Bar chart represents the mean maximal instantaneous velocity of individual mitochondria that were mobile within astrocytes. $I$, Bar chart represents the mean lengths of astrocyte mitochondria across transfection conditions (mobile and stationary). ${ }^{*} p<0.05$ (ANOVA with Bonferroni's multiple comparisons test).

$\mathrm{Ca}^{2+}$ signaling events within subfields containing multiple processes from these astrocytes for a period of $15 \mathrm{~min}$. Expression of Miro ${ }^{\mathrm{KK}}$ increased the frequency of the $\mathrm{Ca}^{2+}$ spikes by $\sim 25 \%$ and nearly doubled the time constant (Fig. $7 A, D$ ). There was no effect on amplitude (Fig. $7 B$ ) or spatial spread (Fig. 7C). These results suggest that the $\mathrm{Ca}^{2+}$-sensitive positioning of mitochondria (via Miro proteins) at domains of elevated $\mathrm{Ca}^{2+}$ is important for controlling the rate of recovery of the $\mathrm{Ca}^{2+}$ transients and the frequency of $\mathrm{Ca}^{2+}$ signals in the astrocyte processes.

Depolarization of mitochondria alters the kinetics of $\left[\mathrm{Ca}^{2+}\right]_{\mathrm{i}}$ transients within the astrocyte

Mitochondria accumulate $\mathrm{Ca}^{2+}$ using the proton electrochemical gradient established during electron transport (Vasington and Murphy, 1962; Rizzuto et al., 1992; Kirichok et al., 2004). Therefore, we examined the effect of collapsing this gradient using the proton ionophore, FCCP (Reyes and Parpura, 2008). Application of FCCP caused a rapid (within seconds) increase in $\left[\mathrm{Ca}^{2+}\right]_{\mathrm{i}}$ that was long-lasting (minutes) (Fig. 8A,B). After this broad increase in $\left[\mathrm{Ca}^{2+}\right]$ dissipated, spontaneous events reemerge. These $\mathrm{Ca}^{2+}$ spikes propagate nearly twofold further than observed in control (Fig. $8 D ; p<0.0001$, Kolmorogov-Smirnov test), their half-lives are prolonged (Fig. $8 E ; p=0.0004$, Kolmorogov-Smirnov test) and peak amplitude decreased (Fig. $8 C ; p<0.0001$, Kolmorogov-Smirnov test). The rapid release of $\mathrm{Ca}^{2+}$ following FCCP treatment (Fig. 8A,B) suggests that astrocytic mitochondria accumulate $\mathrm{Ca}^{2+}$. The effects on the properties of the $\mathrm{Ca}^{2+}$ spikes are consistent with the hypothesis that mitochondrial $\mathrm{Ca}^{2+}$ uptake contributes to the spatial restriction of $\mathrm{Ca}^{2+}$ signals within the astrocyte processes.

Given the problems inherent in either generalized inhibition of mitochondrial electron transfer (FCCP) or adaptive changes in mitochondrial positioning following transfection (Miro ${ }^{\mathrm{KK}}$ ), we used a third paradigm to examine the role of mitochondrial positioning in controlling $\mathrm{Ca}^{2+}$ in astrocytic processes; photoablation of individual mitochondria. Astrocytes were transfected with the $\mathrm{Ca}^{2+}$-indictor LCK-GCamp5G (Fig. 9B) and the photosensitizing construct KillerRed targeted to the mitochondrial matrix 
(KillerRed-mito; Fig. 9A). This construct has been used previously to locally eliminate mitochondria and is thought to act via ROS production (Williams et al., 2013a; Wong and Holzbaur, 2014). Exposure to $405 \mathrm{~nm}$ light ( $2 \mathrm{~s}$; white arrow) results in a rapid ablation of the mitochondria and frequently ( 8 of 9 cells) an increase in local $\left[\mathrm{Ca}^{2+}\right]_{\mathrm{i}}$. In 5 of 9 cells, this was followed by an increased frequency of calcium spikes at or adjacent to the ablation site (Fig. 9B). These $\mathrm{Ca}^{2+}$ transients are $\sim 1.5$-fold larger (Fig. $9 C$; $p=0.037$; Mann-Whitney test), spread nearly threefold farther (Fig. 9D; $p<$ 0.0001; Mann-Whitney test), and are slower to decay (Fig. 9E; $p=0.045$; Man$\mathrm{n}$-Whitney test) than are $\mathrm{Ca}^{2+}$ transients before photoablation. These results suggest that individual mitochondria within the astrocyte processes accumulate $\mathrm{Ca}^{2+}$ and that the positioning of mitochondria is important for constraining $\mathrm{Ca}^{2+}$ signals within astrocyte processes.

Although each of these approaches has its limitations, in combination, these results show that the astrocytic mitochondria are actively buffering $\mathrm{Ca}^{2+}$ and that the accurate positioning of mitochondria at sites of elevated $\mathrm{Ca}^{2+}$ activity is important in constraining these $\left[\mathrm{Ca}^{2+}\right]_{\mathrm{i}}$ increases within the astrocyte processes.

\section{Discussion}

Previously, we showed that mitochondria are present in the processes of astrocytes, that they are mobile, and that their mobility is increased following inhibition of neuronal activity, astrocytic glutamate uptake, or reversed $\mathrm{Na}^{+} / \mathrm{Ca}^{2+}$-exchange (Jackson et al., 2014). Indeed, neuronal activity regulates the accumulation of mitochondria near glutamate transporter clusters that appose synapses in organotypic slices (Jackson et al., 2014) and in culture (Ugbode et al., 2014). Here we sought to address the molecular mechanisms regulating the arrest of mitochondria at these sites. We showed that inhibiting neuronal activity, glutamate uptake, or $\mathrm{Na}^{+} / \mathrm{Ca}^{2+}$-exchange all decrease basal $\left[\mathrm{Ca}^{2+}\right]_{\mathrm{i}}$ and modulate spontaneous $\mathrm{Ca}^{2+}$ signaling within the astrocyte processes. We demonstrated that the $\mathrm{Ca}^{2+}$-sensitive adaptor proteins Mirol and Miro2 are expressed in astrocytes and regulate mitochondrial mobility within astrocyte processes. We showed that mitochondrial depolarization (FCCP) decreases the rate of $\mathrm{Ca}^{2+}$ clearance from the cytosol and increases the spread of $\mathrm{Ca}^{2+}$ signals. Last, we demonstrated that the ability of mitochondria to influence $\mathrm{Ca}^{2+}$ dynamics is dependent upon active positioning of the mitochondria in a Miro- and $\mathrm{Ca}^{2+}$-dependent fashion.

Functionally and morphologically, astrocytes are intimately integrated into the neuronal circuitry. In the mouse cortex, a single astrocyte contacts thousands of synapses (Bushong et al., 2002) and ensheaths multiple cell bodies (Halassa et al., 2007). Astrocytes express many neurotransmitter receptors and transporters that allow them to sense and respond to neuronal (or other) stimuli (Zhang et al., 2014; for review, see Rusakov, 2015). Astrocytes respond to many/most of these factors through increase in $\left[\mathrm{Ca}^{2+}\right]_{\mathrm{i}}$, suggesting an essential role for changes in

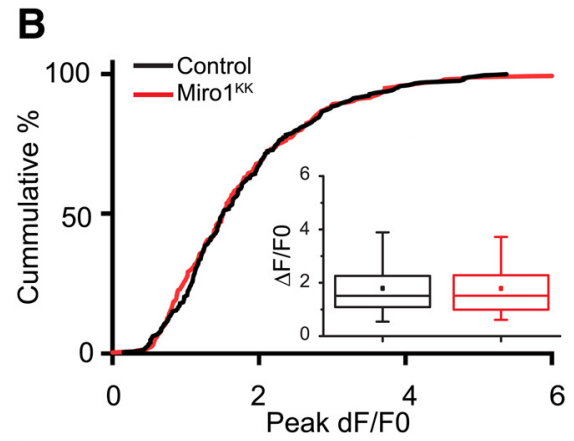

D

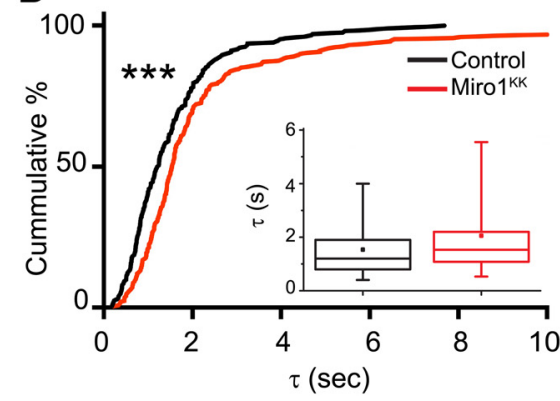

Figure 7. Calcium-dependent positioning of mitochondria is important for mitochondrial $\mathrm{Ca}^{2+}$ buffering. Astrocytes in orga-

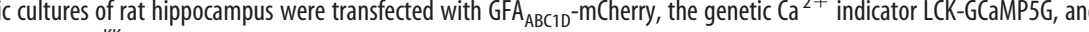
processes, 7 cells) or myc-vector (black; $n=49$ processes, 6 cells). Results are mean \pm SEM. ${ }^{\#} p<0.05$ (Student's unpaired $95 \%$ range. Shoulders of boxes indicate $25 \%-75 \%$ intervals. Median of data is highlighted by horizontal line. ${ }^{* * *} p<0.0001$

$\left[\mathrm{Ca}^{2+}\right]_{\mathrm{i}}$ in the astrocytic response (for review, see Rusakov, 2015). Indeed, many of these $\mathrm{Ca}^{2+}$ signals have been linked to changes in synaptic plasticity and local blood flow, although controversies regarding the source of the $\mathrm{Ca}^{2+}$ signals and the physiologic relevance of these signals have arisen (Araque et al., 2014; Rusakov et al., 2014; Benjamin Kacerovsky and Murai, 2015; Srinivasan et al., 2015; for review, see Attwell et al., 2010).

Until recently, much of the local signaling that occurs within individual processes was not apparent (Shigetomi et al., 2010b). Our results are consistent with previous observations using membrane-tethered indicators that describe highly localized $\mathrm{Ca}^{2+}$ signals within the processes of the astrocyte (Shigetomi et al., 2012, 2013b) that are sensitive to inhibition with a TRPA1 antagonist (Fig. 2G). These $\mathrm{Ca}^{2+}$ transients appear to be uncoordinated temporally between processes but reappear frequently within the same locations, suggesting an underlying spatial organization regulating the genesis of these $\mathrm{Ca}^{2+}$ signals. Understanding how these local signals are generated, how they are compartmentalized, and under what circumstances this compartmentalization is changed will be important to understanding how this common signal controls both local and global signaling within the astrocyte.

Others (Grosche et al., 1999; Perea and Araque, 2005; Shigetomi et al., 2010b; Di Castro et al., 2011; Panatier et al., 2011; Reeves et al., 2011; Srinivasan et al., 2015) have observed [ $\mathrm{Ca}^{2+}$ ] signals that are spatially discrete, rarely propagating beyond several microns. While recent research has concentrated on determining how these spatially isolated $\mathrm{Ca}^{2+}$ signals are generated, an equally compelling question is as follows: what are the mecha- 
A

B
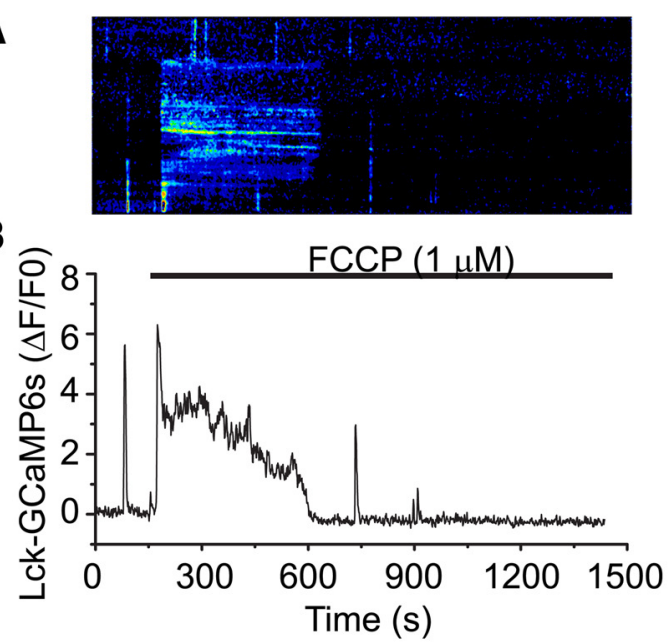

C

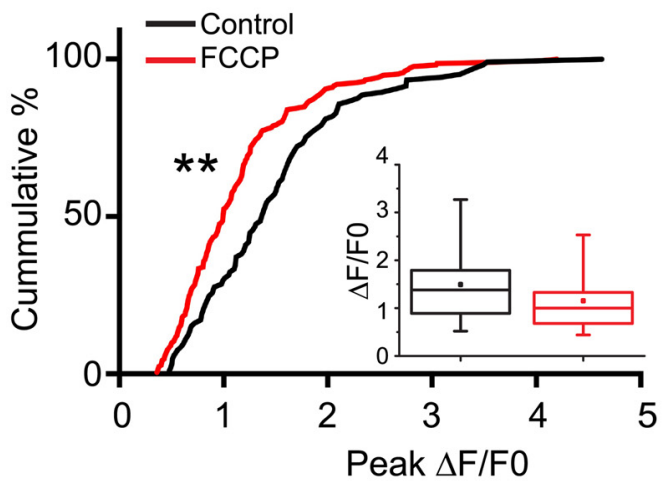

D

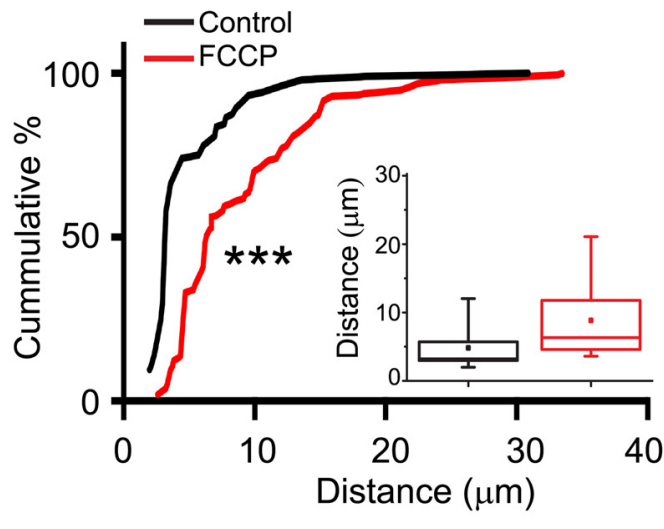

$\mathbf{E}$

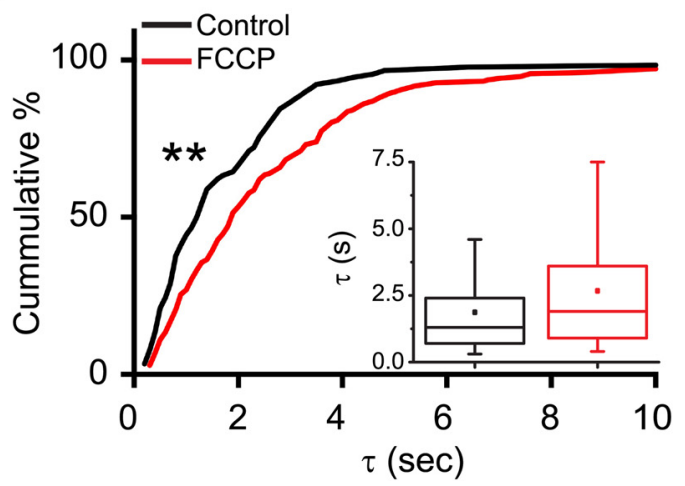

Figure 8. Mitochondria regulate $\mathrm{Ca}^{2+}$ signaling within astrocyte processes. Astrocytes in organotypic cultures of rat hippocampus were transfected with a membrane-targeted-mCherry fluorescent protein driven by a GFAP promoter ( $\left(\mathrm{FF}_{\mathrm{ABC}} \mathrm{D}^{-} \mathrm{mCherry}\right)$ and the genetic $\mathrm{Ca}^{2+}$ indicator LCK-GCaMP5G. Slices were continuously superfused with oxygenated-aCSF. FCCP (1 $\mu \mathrm{M})$ was applied by superfusion as indicated by application bar. Representative kymograph $(\boldsymbol{A})$
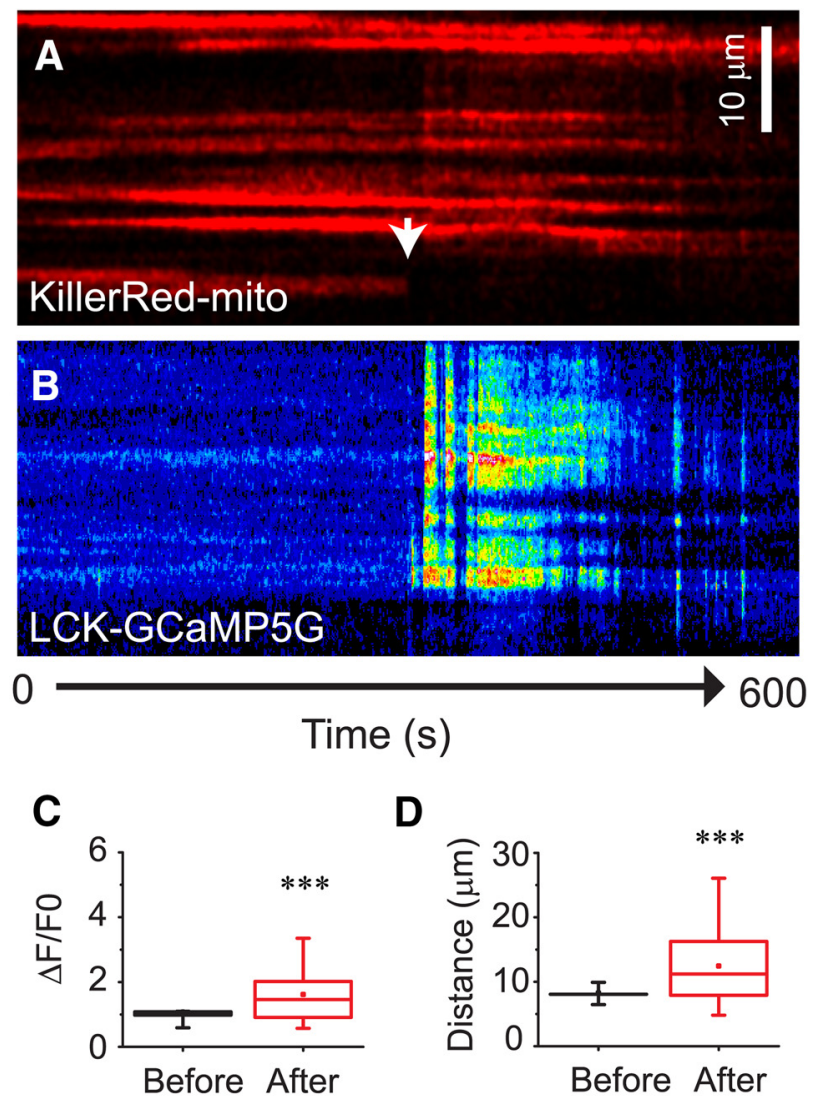

D
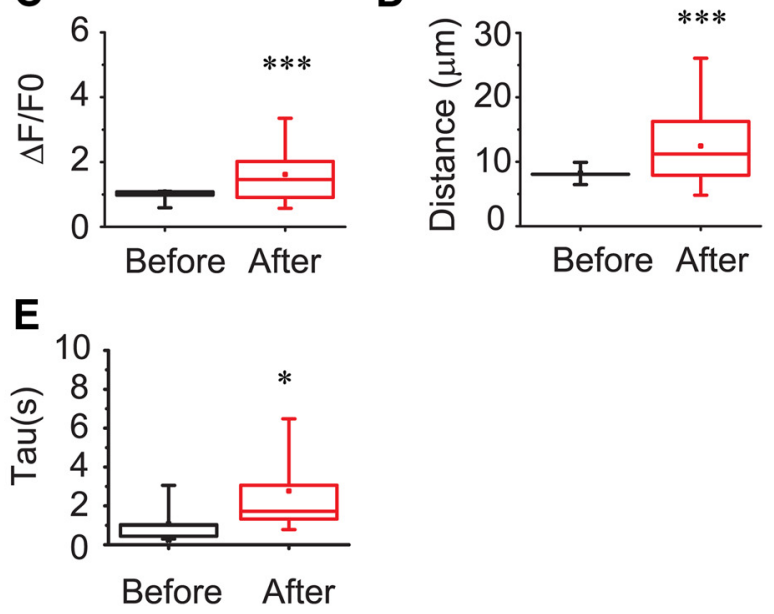

Figure 9. Individual mitochondria limit the $\mathrm{Ca}^{2+}$ excitability of astrocyte processes. Astrocytes in organotypic cultures of rat hippocampus were transfected with pKillerRed-mito $(\boldsymbol{A}$, red) and the genetic $\mathrm{Ca}^{2+}$ indicator LCK-GCaMP5G (B, pseudocolor). Individual mitochondria were photo-ablated by exposure ( $2 \mathrm{~s}$ ) to $405 \mathrm{~nm}$ laser light (white arrow). GCaMP fluorescence was monitored throughout the recording. Box-and-whisker plots depict amplitude (C, peak $\Delta F / F 0)$, distance propagated $(\boldsymbol{D}, \mu \mathrm{m})$, and time constants $\left(\boldsymbol{E}\right.$, seconds) of individual $\mathrm{Ca}^{2+}$ transients before and after photo-ablation of individual mitochondria. Error bars indicate $5 \%-95 \%$ range. Shoulders of boxes indicate $25 \%-75 \%$ intervals. Median of data is highlighted by horizontal line. ${ }^{*} p<0.05$ (by Mann-Whitney test). ${ }^{* *} p<0.0001$ (Mann-Whitney test). $n=12$ and $n=63$ spikes before and after photoablation, respectively ( 7 cells).

nisms that restrict the spatial spread of these signals? Mitochondria have been shown to inhibit the propagation of $\mathrm{Ca}^{2+}$ waves in primary cultures of rat cortical astrocytes (Boitier et al., 1999). Here we demonstrate that mitochondria colocalize with $\mathrm{Ca}^{2+}$

and fluorescence trace $(\boldsymbol{B})$ from an astrocyte processes treated with the proton ionophore (FCCP; $1 \mu \mathrm{M})$. The amplitudes $(\boldsymbol{C}, \Delta \mathrm{F} / \mathrm{F} 0)$, distance traveled $(\boldsymbol{D}, \mu \mathrm{m})$, and kinetics ( $\boldsymbol{E}$, tau, seconds) of the individual $\mathrm{Ca}^{2+}$ transients were quantified before (black) and after application of FCCP (red), and the results are depicted as both cumulative probability distributions and box-andwhisker plots (inset). Error bars indicate 5\%-95\% range. Shoulders of boxes indicate $25 \%-75 \%$ intervals. Median of data is highlighted by horizontal line. ${ }^{* *} p<0.001$ (Kolmorogov-Smirnov test). ${ }^{* * *} p<0.0001$ (Kolmorogov-Smirnov test). $n=90$ and $n=208$ spikes (81 processes, 5 cells) for control and FCCP-treated conditions. 

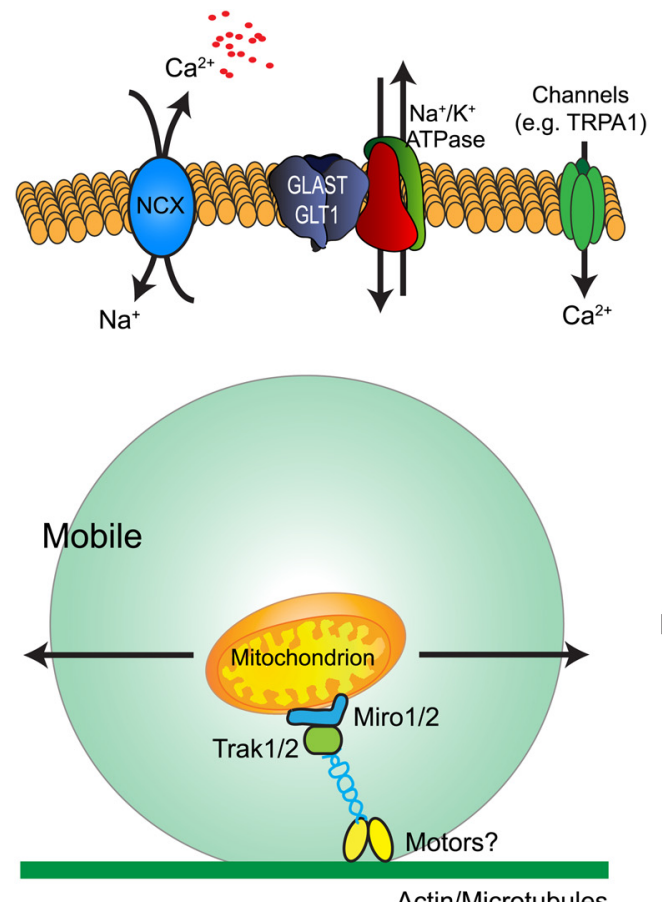

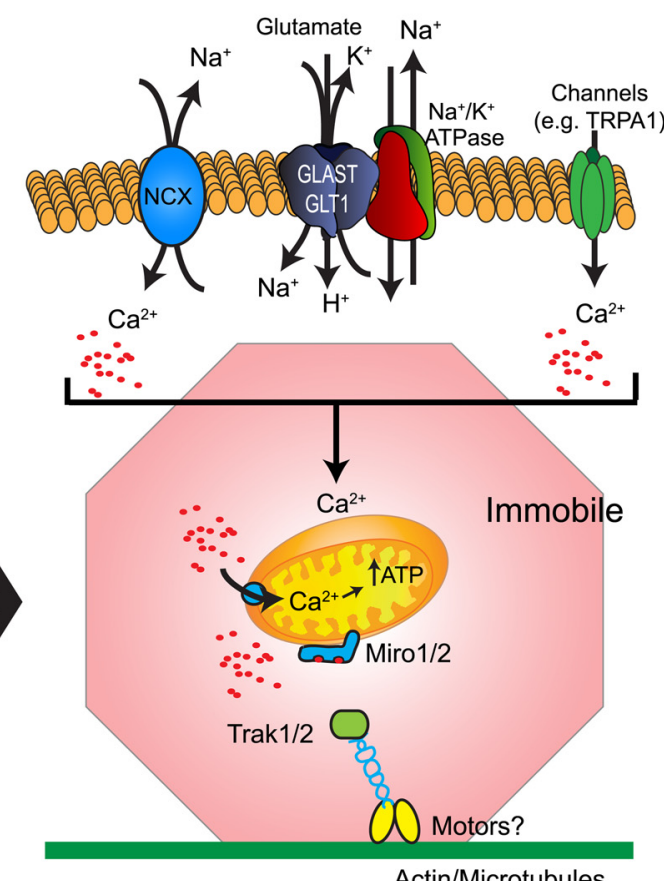

Actin/Microtubules

Figure 10. Model: Transporter-dependent immobilization of mitochondria via $\mathrm{Ca}^{2+}$ and Miro protein. Neuronal activity results in an increased release of glutamate (and other transmitters). Glutamate is cleared into the astrocyte accompanied by the movement of $3 \mathrm{Na}^{+}$ions and a $\mathrm{H}^{+}$, and the countertransport of a $\mathrm{K}^{+}$ion (Zerangue and Kavanaugh, 1996). This influx of $\mathrm{Na}{ }^{+}$is sufficient to cause reversed operation of the plasma membrane $\mathrm{Na}^{+} / \mathrm{Ca}^{2+}$ exchanger, resulting in an increase in the basal $\left[\mathrm{Ca}^{2+}\right.$ ] within the fine astrocyte processes (Langer and Rose, 2009; Reyes et al., 2012; Magi et al., 2013; Rojas et al., 2013). Additional processes (e.g., TRPA1) also contribute to basal $\left[\mathrm{Ca}^{2+}\right]_{\mathrm{i}}$ (Shigetomi et al., 2012). Increases in basal $\left[\mathrm{Ca}^{2+}\right]_{\mathrm{i}}$ result in the arrest of mitochondria in a Miro protein-dependent fashion (Macaskill et al., 2009; Wang and Schwarz, 2009). Immobilized mitochondria are available to accumulate $\mathrm{Ca}^{2+}$ (Rizzuto et al., 2012; Williams et al., 2013b). Increases in mitochondrial [ $\mathrm{Ca}^{2+}$ ] may stimulate ATP production via TCA cycle activation (Wan et al., 1989; Denton, 2009). Decreases in cytosolic [C ${ }^{2+}$ ] permit the reengagement of mitochondria with the motor apparatus with the subsequent reinitiation of motility (Macaskill et al., 2009; Wang and Schwarz, 2009).

signals in astrocyte processes and that uncoupling mitochondria increases the spatial spread of spontaneous, localized $\mathrm{Ca}^{2+}$ signals. This effect may be direct, via reduced mitochondrial $\mathrm{Ca}^{2+}$ uptake, or indirect by depletion of local ATP to fuel the sarcoplamic/endplasmic reticulum or plasma membrane $\mathrm{Ca}^{2+}$ ATPases (SERCA or PMCA, respectively) pumps. Nevertheless, it implies that mitochondria play an important role in the functional compartmentalization of $\mathrm{Ca}^{2+}$ signals in astrocytes. It will be interesting to examine how other clearance mechanisms (PMCAs, SERCAs, forward mode $\mathrm{Na}^{+} / \mathrm{Ca}^{2+}$ exchanger [NCX]), endogenous buffers, and astrocyte geometry contribute to the spatial and temporal compartmentalization of these calcium signals.

In addition to these highly localized events, we describe mechanisms regulating basal $\left[\mathrm{Ca}^{2+}\right]_{i}$ within the processes of the astrocyte. In particular, we describe a significant contribution of reversed- $-\mathrm{Na}^{+} / \mathrm{Ca}^{2+}$ exchange to regulating basal $\left[\mathrm{Ca}^{2+}\right]_{\mathrm{i}}$. The NCX is a bidirectional exchanger that couples the inward movement of three $\mathrm{Na}^{+}$ions to the outward movement of one $\mathrm{Ca}^{2+}$ ion (Blaustein and Lederer, 1999). All three NCX isoforms are enriched at perisynaptic distal astrocyte processes (Minelli et al., 2007). The reversal potential of the NCX in astrocytes is close to the resting membrane potential (Kirischuk et al., 1997; Reyes et al., 2012), such that NCX can rapidly operate in the so-called reverse mode $\left(\mathrm{Na}^{+}\right.$out $/ \mathrm{Ca}^{2+}$ in) in response to small $\mathrm{Na}^{+}$loads, such as occur with glutamate transport (Langer and Rose, 2009). We observed a decrease in basal $\left[\mathrm{Ca}^{2+}\right]_{\mathrm{i}}$ following treatment with TFB-TBOA (Fig. $1 B$ ) that is phenocopied by direct inhibition of NCX with YM-244769 (Fig. 1C), suggesting a persistent activation of NCX subsequent to neuronal activity and glutamate up- take. This is consistent with results in primary cultures of astrocytes (Reyes et al., 2012; Magi et al., 2013; Rojas et al., 2013). Other mechanisms (TRPA1) regulating basal $\left[\mathrm{Ca}^{2+}\right]_{\mathrm{i}}$ have been implicated in controlling the surface expression of the GABA transporter GAT (Shigetomi et al., 2012) and the release of D-serine (Shigetomi et al., 2013a). Activation of the reversed mode of the NCX might couple glutamate uptake to downstream signaling via $\mathrm{Ca}^{2+}$.

In neurons, mitochondria are distributed to match energetic supply and $\mathrm{Ca}^{2+}$ buffering to the demand imposed by neuronal signaling. In other systems, a key mediator of mitochondrial movement and positioning is the Miro proteins (Saotome et al., 2008). These $\mathrm{Ca}^{2+}$-sensitive outer-membrane mitochondrial proteins link mitochondria to motor proteins (kinesins) through TRAK adaptor proteins. Increases in $\left[\mathrm{Ca}^{2+}\right]_{\mathrm{i}}$ lead to immobilization of mitochondria in a Miro protein-dependent manner (Fig. 10) (for review, see Sheng and Cai, 2012; Schwarz, 2013). Here, we demonstrate that the Miro proteins (Miro1 and Miro2) are expressed in astrocytes. In astrocytes, the percentage of mitochondria that are mobile is low (Fig. $6 F$ ). Exogenous expression increases mitochondrial movement, suggesting that Miro expression might limit baseline mobility of astrocytic mitochondria. Increased mitochondrial movement with expression of $\mathrm{Ca}^{2+}$ insensitive Miro mutants suggests that mitochondrial mobility is controlled by intracellular $\mathrm{Ca}^{2+}$ concentration $\left(\left[\mathrm{Ca}^{2+}\right]_{\mathrm{i}}\right)$ and that mitochondrial movement is inhibited at relatively low levels of $\mathrm{Ca}^{2+}$, as would be expected in astrocytes in unstimulated slices. Interestingly, Ugbode et al. (2014) showed that the expression of the Miro-binding partner TRAK increases when astrocytes are cocultured with neurons. These results suggest that, as in 
neurons, Miro proteins regulate the distribution of mitochondria in astrocytes at domains of elevated activity or $\left[\mathrm{Ca}^{2+}\right]_{i}$.

Mitochondria play complex roles in cells. They represent a potential mechanism to locally supply energy via the TCA cycle and oxidative phosphorylation, integrate numerous cues related to cell survival, and regulate local $\mathrm{Ca}^{2+}$ signaling (Jacobson and Duchen, 2004). Many of these roles are interconnected.

Mitochondria import $\mathrm{Ca}^{2+}$ via a $\mathrm{Ca}^{2+}$-sensitive uniporter (MCU). This process is driven by the large negative membrane potential $(\sim-180 \mathrm{mV})$ established across the inner mitochondrial membrane (Kirichok et al., 2004). This process occurs in lieu of proton reentry via the ATP synthase (Rizzuto et al., 2012). Accumulated $\mathrm{Ca}^{2+}$ is released into the cytosol via a mitochondrial $\mathrm{Na}^{+} / \mathrm{Ca}^{2+}$-exchanger (Baron and Thayer, 1997; Nicholls and Budd, 2000). These processes allow mitochondria to blunt the amplitude, modulate the duration, and spatially restrict the propagation of $\mathrm{Ca}^{2+}$ signals. Several lines of evidence from our current study suggest a role for mitochondria in regulating $\mathrm{Ca}^{2+}$ signaling within the astrocyte processes. First, application of the proton ionophore FCCP (Fig. 8) or photoablation of individual mitochondria (Fig. 9) resulted in large increases in $\left[\mathrm{Ca}^{2+}\right]_{\mathrm{i}}$, suggesting that mitochondria in the processes accumulate $\mathrm{Ca}^{2+}$. Second, mitochondrial uncoupling increased the time constant and spatial spread of spontaneous $\mathrm{Ca}^{2+}$ transients within the astrocyte processes (Fig. $8 D, E$ ), consistent with the loss of a $\mathrm{Ca}^{2+}$ buffer. Last, inhibiting the $\mathrm{Ca}^{2+}$-dependent arrest of mitochondria (Miro ${ }^{\mathrm{KK}}$; Fig. 7) increased the frequency of $\mathrm{Ca}^{2+}$ events and increased the time constant of decay of these transients, suggesting that the $\mathrm{Ca}^{2+}$-dependent positioning of mitochondria is important for their ability to efficiently buffer $\mathrm{Ca}^{2+}$ signals.

In addition to shaping $\mathrm{Ca}^{2+}$ signals, mitochondrial $\mathrm{Ca}^{2+}$ uptake alters the activity of mitochondria. Mitochondrial $\mathrm{Ca}^{2+}$ uptake increases the production of ATP by activating the $\mathrm{Ca}^{2+}$-sensitive dehydrogenases of the mitochondrial matrix (pyruvate dehydrogenase, isocitrate dehydrogenase, and oxoglutarate dehydrogenase) (Denton et al., 1972; Cárdenas et al., 2010), and the adenine nucleotide translocator (Moreno-Sánchez, 1985). Additionally, $\mathrm{Ca}^{2+}$ regulates the glutamate/aspartate carrier proteins (citrin and aralar) (Satrústegui et al., 2007). The net result of these activities is an increase in $\mathrm{H}^{+}$transport, respiration, and ATP production. $\mathrm{Ca}^{2+}$-dependent mitochondrial positioning and subsequent mitochondrial $\mathrm{Ca}^{2+}$ uptake might allow mitochondria to sense domains of elevated activity and enable mitochondria to tune ATP production to the local energy requirements of the astrocyte.

Here we describe a mechanism by which astrocytes may transport and retain mitochondria at domains of elevated activity (e.g., perisynaptic regions enriched in glutamate transporters) via increases in $\left[\mathrm{Ca}^{2+}\right]$. Miro protein-mediated arrest of mitochondria and subsequent $\mathrm{Ca}^{2+}$ uptake by the mitochondria serve to compartmentalize spontaneous $\mathrm{Ca}^{2+}$ signals within the astrocyte processes and provide local energetic support.

\section{References}

Akerboom J, Chen TW, Wardill TJ, Tian L, Marvin JS, Mutlu S, Calderón NC, Esposti F, Borghuis BG, Sun XR, Gordus A, Orger MB, Portugues R, Engert F, Macklin JJ, Filosa A, Aggarwal A, Kerr RA, Takagi R, Kracun S, et al. (2012) Optimization of a GCaMP calcium indicator for neural activity imaging. J Neurosci 32:13819-13840. CrossRef Medline

Araque A, Carmignoto G, Haydon PG, Oliet SH, Robitaille R, Volterra A (2014) Gliotransmitters travel in time and space. Neuron 81:728-739. CrossRef Medline

Attwell D, Buchan AM, Charpak S, Lauritzen M, Macvicar BA, Newman EA
(2010) Glial and neuronal control of brain blood flow. Nature 468:232243. CrossRef Medline

Baron KT, Thayer SA (1997) CGP37157 modulates mitochondrial $\mathrm{Ca}^{2+}$ homeostasis in cultured rat dorsal root ganglion neurons. Eur J Pharmacol 340:295-300. CrossRef Medline

Barres BA (2008) The mystery and magic of glia: a perspective on their roles in health and disease. Neuron 60:430-440. CrossRef Medline

Benediktsson AM, Schachtele SJ, Green SH, Dailey ME (2005) Ballistic labeling and dynamic imaging of astrocytes in organotypic hippocampal slice cultures. J Neurosci Methods 141:41-53. CrossRef Medline

Benjamin Kacerovsky J, Murai KK (2015) Stargazing: Monitoring subcellular dynamics of brain astrocytes. Neuroscience S0306.

Bernardinelli Y, Salmon C, Jones EV, Farmer WT, Stellwagen D, Murai KK (2011) Astrocytes display complex and localized calcium responses to single-neuron stimulation in the hippocampus. J Neurosci 31:89058919. CrossRef Medline

Birsa N, Norkett R, Wauer T, Mevissen TE, Wu HC, Foltynie T, Bhatia K, Hirst WD, Komander D, Plun-Favreau H, Kittler JT (2014) Lysine 27 ubiquitination of the mitochondrial transport protein Miro is dependent on serine 65 of the Parkin ubiquitin ligase. J Biol Chem 289:14569-14582. CrossRef Medline

Blaustein MP, Lederer WJ (1999) Sodium/calcium exchange: its physiological implications. Physiol Rev 79:763-854. Medline

Boitier E, Rea R, Duchen MR (1999) Mitochondria exert a negative feedback on the propagation of intracellular $\mathrm{Ca}^{2+}$ waves in rat cortical astrocytes. J Cell Biol 145:795-808. CrossRef Medline

Brickley K, Stephenson FA (2011) Trafficking kinesin protein (TRAK)mediated transport of mitochondria in axons of hippocampal neurons. J Biol Chem 286:18079-18092. CrossRef Medline

Bushong EA, Martone ME, Jones YZ, Ellisman MH (2002) Protoplasmic astrocytes in CA1 stratum radiatum occupy separate anatomical domains. J Neurosci 22:183-192. Medline

Cahoy JD, Emery B, Kaushal A, Foo LC, Zamanian JL, Christopherson KS, Xing Y, Lubischer JL, Krieg PA, Krupenko SA, Thompson WJ, Barres BA (2008) A transcriptome database for astrocytes, neurons, and oligodendrocytes: a new resource for understanding brain development and function. J Neurosci 28:264-278. CrossRef Medline

Cárdenas C, Miller RA, Smith I, Bui T, Molgó J, Müller M, Vais H, Cheung KH, Yang J, Parker I, Thompson CB, Birnbaum MJ, Hallows KR, Foskett JK (2010) Essential regulation of cell bioenergetics by constitutive InsP3 receptor $\mathrm{Ca}^{2+}$ transfer to mitochondria. Cell 142:270-283. CrossRef Medline

Chen TW, Wardill TJ, Sun Y, Pulver SR, Renninger SL, Baohan A, Schreiter ER, Kerr RA, Orger MB, Jayaraman V, Looger LL, Svoboda K, Kim DS (2013) Ultrasensitive fluorescent proteins for imaging neuronal activity. Nature 499:295-300. CrossRef Medline

Chen J, Joshi SK, DiDomenico S, Perner RJ, Mikusa JP, Gauvin DM, Segreti JA, Han P, Zhang XF, Niforatos W, Bianchi BR, Baker SJ, Zhong C, Simler GH, McDonald HA, Schmidt RG, McGaraughty SP, Chu KL, Faltynek CR, Kort ME, Reilly RM, Kym PR (2011) Selective blockade of TRPA1 channel attenuates pathological pain without altering noxious cold sensation or body temperature regulation. Pain 152:1165-1172. CrossRef Medline

Cheng H, Song LS, Shirokova N, González A, Lakatta EG, Ríos E, Stern MD (1999) Amplitude distribution of calcium sparks in confocal images: theory and studies with an automatic detection method. Biophys J 76:606617. CrossRef Medline

Cornell-Bell AH, Finkbeiner SM, Cooper MS, Smith SJ (1990) Glutamate induces calcium waves in cultured astrocytes: long-range glial signaling. Science 247:470-473. CrossRef Medline

Csordás G, Thomas AP, Hajnóczky G (1999) Quasi-synaptic calcium signal transmission between endoplasmic reticulum and mitochondria. EMBO J 18:96-108. CrossRef Medline

Denton RM (2009) Regulation of mitochondrial dehydrogenases by calcium ions. Biochim Biophys Acta 1787:1309-1316. CrossRef Medline

Denton RM, Randle PJ, Martin BR (1972) Stimulation by calcium ions of pyruvate dehydrogenase phosphate phosphatase. Biochem J 128:161163. CrossRef Medline

Di Castro MA, Chuquet J, Liaudet N, Bhaukaurally K, Santello M, Bouvier D, Tiret P, Volterra A (2011) Local $\mathrm{Ca}^{2+}$ detection and modulation of synaptic release by astrocytes. Nat Neurosci 14:1276-1284. CrossRef Medline 
Fatatis A, Russell JT (1992) Spontaneous changes in intracellular calcium concentration in type I astrocytes from rat cerebral cortex in primary culture. Glia 5:95-104. CrossRef Medline

Fransson A, Ruusala A, Aspenström P (2003) Atypical Rho GTPases have roles in mitochondrial homeostasis and apoptosis. J Biol Chem 278:64956502. CrossRef Medline

Fransson S, Ruusala A, Aspenström P (2006) The atypical Rho GTPases Miro-1 and Miro-2 have essential roles in mitochondrial trafficking. Biochem Biophys Res Commun 344:500-510. CrossRef Medline

Frederick RL, McCaffery JM, Cunningham KW, Okamoto K, Shaw JM (2004) Yeast Miro GTPase, Gemlp, regulates mitochondrial morphology via a novel pathway. J Cell Biol 167:87-98. CrossRef Medline

Garlin AB, Sinor AD, Sinor JD, Jee SH, Grinspan JB, Robinson MB (1995) Pharmacology of sodium-dependent high-affinity L- $\left[{ }^{3} \mathrm{H}\right]$ glutamate transport in glial cultures. J Neurochem 64:2572-2580. CrossRef Medline

Genda EN, Jackson JG, Sheldon AL, Locke SF, Greco TM, O'Donnell JC, Spruce LA, Xiao R, Guo W, Putt M, Seeholzer S, Ischiropoulos H, Robinson MB (2011) Co-compartmentalization of the astroglial glutamate transporter, GLT-1, with glycolytic enzymes and mitochondria. J Neurosci 31:18275-18288. CrossRef Medline

Glater EE, Megeath LJ, Stowers RS, Schwarz TL (2006) Axonal transport of mitochondria requires milton to recruit kinesin heavy chain and is light chain independent. J Cell Biol 173:545-557. CrossRef Medline

Grosche J, Matyash V, Möller T, Verkhratsky A, Reichenbach A, Kettenmann H (1999) Microdomains for neuron-glia interaction: parallel fiber signaling to Bergmann glial cells. Nat Neurosci 2:139-143. CrossRef Medline

Halassa MM, Haydon PG (2010) Integrated brain circuits: astrocytic networks modulate neuronal activity and behavior. Annu Rev Physiol 72: 335-355. CrossRef Medline

Halassa MM, Fellin T, Takano H, Dong JH, Haydon PG (2007) Synaptic islands defined by the territory of a single astrocyte. J Neurosci 27:64736477. CrossRef Medline

Haustein MD, Kracun S, Lu XH, Shih T, Jackson-Weaver O, Tong X, Xu J, Yang XW, O'Dell TJ, Marvin JS, Ellisman MH, Bushong EA, Looger LL, Khakh BS (2014) Conditions and constraints for astrocyte calcium signaling in the hippocampal mossy fiber pathway. Neuron 82:413-429. CrossRef Medline

Huang YH, Sinha SR, Tanaka K, Rothstein JD, Bergles DE (2004) Astrocyte glutamate transporters regulate metabotropic glutamate receptormediated excitation of hippocampal interneurons. J Neurosci 24:45514559. CrossRef Medline

Isaacson JS, Nicoll RA (1993) The uptake inhibitor L-trans-PDC enhances responses to glutamate but fails to alter the kinetics of excitatory synaptic currents in the hippocampus. J Neurophysiol 70:2187-2191. Medline

Jabaudon D, Shimamoto K, Yasuda-Kamatani Y, Scanziani M, Gähwiler BH, Gerber U (1999) Inhibition of uptake unmasks rapid extracellular turnover of glutamate of nonvesicular origin. Proc Natl Acad Sci U S A 96: 8733-8738. CrossRef Medline

Jackson JG, O’Donnell JC, Takano H, Coulter DA, Robinson MB (2014) Neuronal activity and glutamate uptake decrease mitochondrial mobility in astrocytes and position mitochondria near glutamate transporters. J Neurosci 34:1613-1624. CrossRef Medline

Jacobson J, Duchen MR (2004) Interplay between mitochondria and cellular calcium signalling. Mol Cell Biochem 256:209-218. CrossRef Medline

Kirichok Y, Krapivinsky G, Clapham DE (2004) The mitochondrial calcium uniporter is a highly selective ion channel. Nature 427:360-364. CrossRef Medline

Kirischuk S, Kettenmann H, Verkhratsky A (1997) $\mathrm{Na}^{+} / \mathrm{Ca}^{2+}$ exchanger modulates kainate-triggered $\mathrm{Ca}^{2+}$ signaling in Bergmann glial cells in situ. FASEB J 11:566-572. Medline

Kornmann B, Osman C, Walter P (2011) The conserved GTPase Gem1 regulates endoplasmic reticulum-mitochondria connections. Proc Natl Acad Sci U S A 108:14151-14156. CrossRef Medline

Langer J, Rose CR (2009) Synaptically induced sodium signals in hippocampal astrocytes in situ. J Physiol 587:5859-5877. CrossRef Medline

Li Z, Okamoto K, Hayashi Y, Sheng M (2004) The importance of dendritic mitochondria in the morphogenesis and plasticity of spines and synapses. Cell 119:873-887. CrossRef Medline

Macaskill AF, Rinholm JE, Twelvetrees AE, Arancibia-Carcamo IL, Muir J, Fransson A, Aspenstrom P, Attwell D, Kittler JT (2009) Mirol is a cal- cium sensor for glutamate receptor-dependent localization of mitochondria at synapses. Neuron 61:541-555. CrossRef Medline

Magi S, Arcangeli S, Castaldo P, Nasti AA, Berrino L, Piegari E, Bernardini R, Amoroso S, Lariccia V (2013) Glutamate-induced ATP synthesis: relationship between plasma membrane $\mathrm{Na}^{+} / \mathrm{Ca}^{2+}$ exchanger and excitatory amino acid transporters in brain and heart cell models. Mol Pharmacol 84:603-614. CrossRef Medline

Marchaland J, Calì C, Voglmaier SM, Li H, Regazzi R, Edwards RH, Bezzi P (2008) Fast subplasma membrane $\mathrm{Ca}^{2+}$ transients control exoendocytosis of synaptic-like microvesicles in astrocytes. J Neurosci 28: 9122-9132. CrossRef Medline

McAllister AK (2004) Biolistic transfection of cultured organotypic brain slices. Methods Mol Biol 245:197-206. Medline

Meijering E, Dzyubachyk O, Smal I (2012) Methods for cell and particle tracking. Methods Enzymol 504:183-200. CrossRef Medline

Min R, Nevian T (2012) Astrocyte signaling controls spike timingdependent depression at neocortical synapses. Nat Neurosci 15:746-753. CrossRef Medline

Minelli A, Castaldo P, Gobbi P, Salucci S, Magi S, Amoroso S (2007) Cellular and subcellular localization of $\mathrm{Na}^{+}-\mathrm{Ca}^{2+}$ exchanger protein isoforms, NCX1, NCX2, and NCX3 in cerebral cortex and hippocampus of adult rat. Cell Calcium 41:221-234. CrossRef Medline

Moreno-Sánchez R (1985) Contribution of the translocator of adenine nucleotides and the ATP synthase to the control of oxidative phosphorylation and arsenylation in liver mitochondria. J Biol Chem 260:1255412560. Medline

Navarrete M, Perea G, Maglio L, Pastor J, García de Sola R, Araque A (2013) Astrocyte calcium signal and gliotransmission in human brain tissue. Cereb Cortex 23:1240-1246. CrossRef Medline

Nedergaard M (1994) Direct signaling from astrocytes to neurons in cultures of mammalian brain cells. Science 263:1768-1771. CrossRef Medline

Nett WJ, Oloff SH, McCarthy KD (2002) Hippocampal astrocytes in situ exhibit calcium oscillations that occur independent of neuronal activity. J Neurophysiol 87:528-537. Medline

Nicholls DG, Budd SL (2000) Mitochondria and neuronal survival. Physiol Rev 80:315-360. Medline

Ohno N, Kidd GJ, Mahad D, Kiryu-Seo S, Avishai A, Komuro H, Trapp BD (2011) Myelination and axonal electrical activity modulate the distribution and motility of mitochondria at CNS nodes of Ranvier. J Neurosci 31:7249-7258. CrossRef Medline

Otsu Y, Couchman K, Lyons DG, Collot M, Agarwal A, Mallet JM, Pfrieger FW, Bergles DE, Charpak S (2015) Calcium dynamics in astrocyte processes during neurovascular coupling. Nat Neurosci 18:210-218. CrossRef Medline

Panatier A, Vallée J, Haber M, Murai KK, Lacaille JC, Robitaille R (2011) Astrocytes are endogenous regulators of basal transmission at central synapses. Cell 146:785-798. CrossRef Medline

Parpura V, Basarsky TA, Liu F, Jeftinija K, Jeftinija S, Haydon PG (1994) Glutamate-mediated astrocyte-neuron signalling. Nature 369:744-747. CrossRef Medline

Perea G, Araque A (2005) Properties of synaptically evoked astrocyte calcium signal reveal synaptic information processing by astrocytes. J Neurosci 25:2192-2203. CrossRef Medline

Pérez-Alvarez A, Araque A, Martín ED (2013) Confocal microscopy for astrocyte in vivo imaging: recycle and reuse in microscopy. Front Cell Neurosci 7:51. CrossRef Medline

Petzold GC, Murthy VN (2011) Role of astrocytes in neurovascular coupling. Neuron 71:782-797. CrossRef Medline

Petzold GC, Albeanu DF, Sato TF, Murthy VN (2008) Coupling of neural activity to blood flow in olfactory glomeruli is mediated by astrocytic pathways. Neuron 58:897-910. CrossRef Medline

Reeves AM, Shigetomi E, Khakh BS (2011) Bulk loading of calcium indicator dyes to study astrocyte physiology: key limitations and improvements using morphological maps. J Neurosci 31:9353-9358. CrossRef Medline

Reyes RC, Parpura V (2008) Mitochondria modulate $\mathrm{Ca}^{2+}$-dependent glutamate release from rat cortical astrocytes. J Neurosci 28:9682-9691. CrossRef Medline

Reyes RC, Verkhratsky A, Parpura V (2012) Plasmalemmal Na ${ }^{+} / \mathrm{Ca}^{2+}$ exchanger modulates $\mathrm{Ca}^{2+}$-dependent exocytotic release of glutamate from rat cortical astrocytes. ASN Neuro 4:piie00075. CrossRef Medline

Rizzuto R, Simpson AW, Brini M, Pozzan T (1992) Rapid changes of mito- 
chondrial $\mathrm{Ca}^{2+}$ revealed by specifically targeted recombinant aequorin. Nature 358:325-327. CrossRef Medline

Rizzuto R, De Stefani D, Raffaello A, Mammucari C (2012) Mitochondria as sensors and regulators of calcium signalling. Nat Rev Mol Cell Biol 13: 566-578. CrossRef Medline

Rojas H, Colina C, Ramos M, Benaim G, Jaffe E, Caputo C, Di Polo R (2013) Sodium-calcium exchanger modulates the L-glutamate $\mathrm{Ca}(\mathrm{i})(2+)$ signalling in type-1 cerebellar astrocytes. Adv Exp Med Biol 961:267-274. CrossRef Medline

Rusakov DA (2015) Disentangling calcium-driven astrocyte physiology. Nat Rev Neurosci 16:226-233. CrossRef Medline

Rusakov DA, Bard L, Stewart MG, Henneberger C (2014) Diversity of astroglial functions alludes to subcellular specialisation. Trends Neurosci 37: 228-242. CrossRef Medline

Saotome M, Safiulina D, Szabadkai G, Das S, Fransson A, Aspenstrom P, Rizzuto R, Hajnóczky G (2008) Bidirectional $\mathrm{Ca}^{2+}$-dependent control of mitochondrial dynamics by the Miro GTPase. Proc Natl Acad Sci U S A 105:20728-20733. CrossRef Medline

Satrústegui J, Pardo B, Del Arco A (2007) Mitochondrial transporters as novel targets for intracellular calcium signaling. Physiol Rev 87:29-67. CrossRef Medline

Schneider CA, Rasband WS, Eliceiri KW (2012) NIH Image to ImageJ: 25 years of image analysis. Nat Methods 9:671-675. CrossRef Medline

Schummers J, Yu H, Sur M (2008) Tuned responses of astrocytes and their influence on hemodynamic signals in the visual cortex. Science 320:16381643. CrossRef Medline

Schwarz TL (2013) Mitochondrial trafficking in neurons. Cold Spring Harbor Perspect Biol 5:a011304. CrossRef Medline

Sheng ZH, Cai Q (2012) Mitochondrial transport in neurons: impact on synaptic homeostasis and neurodegeneration. Nat Rev Neurosci 13: 77-93. CrossRef Medline

Shigetomi E, Kracun S, Khakh BS (2010a) Monitoring astrocyte calcium microdomains with improved membrane-targeted GCaMP reporters. Neuron Glia Biol 6:183-191. CrossRef Medline

Shigetomi E, Kracun S, Sofroniew MV, Khakh BS (2010b) A genetically targeted optical sensor to monitor calcium signals in astrocyte processes. Nat Neurosci 13:759-766. CrossRef Medline

Shigetomi E, Tong X, Kwan KY, Corey DP, Khakh BS (2012) TRPA1 channels regulate astrocyte resting calcium and inhibitory synapse efficacy through GAT-3. Nat Neurosci 15:70-80. CrossRef Medline

Shigetomi E, Jackson-Weaver O, Huckstepp RT, O'Dell TJ, Khakh BS (2013a) TRPAl channels are regulators of astrocyte basal calcium levels and long-term potentiation via constitutive D-serine release. J Neurosci 33:10143-10153. CrossRef Medline

Shigetomi E, Bushong EA, Haustein MD, Tong X, Jackson-Weaver O, Kracun S, Xu J, Sofroniew MV, Ellisman MH, Khakh BS (2013b) Imaging calcium microdomains within entire astrocyte territories and endfeet with GCaMPs expressed using adeno-associated viruses. J Gen Physiol 141: 633-647. CrossRef Medline

Shimamoto K, Sakai R, Takaoka K, Yumoto N, Nakajima T, Amara SG,
Shigeri Y (2004) Characterization of novel L-threo-beta-benzyloxy aspartate derivatives, potent blockers of the glutamate transporters. Mol Pharmacol 65:1008-1015. CrossRef Medline

Srinivasan R, Huang BS, Venugopal S, Johnston AD, Chai H, Zeng H, Golshani P, Khakh BS (2015) Ca signaling in astrocytes from Ip3r2 mice in brain slices and during startle responses in vivo. Nat Neurosci 18:708717. CrossRef Medline

Stephen TL, Gupta-Agarwal S, Kittler JT (2014) Mitochondrial dynamics in astrocytes. Biochem Soc Trans 42:1302-1310. CrossRef Medline

Stowers RS, Megeath LJ, Górska-Andrzejak J, Meinertzhagen IA, Schwarz TL (2002) Axonal transport of mitochondria to synapses depends on milton, a novel Drosophila protein. Neuron 36:1063-1077. CrossRef Medline

Trussell LO, Thio LL, Zorumski CF, Fischbach GD (1988) Rapid desensitization of glutamate receptors in vertebrate central neurons. Proc Natl Acad Sci U S A 85:2834-2838. CrossRef Medline

Ugbode CI, Hirst WD, Rattray M (2014) Neuronal influences are necessary to produce mitochondrial co-localization with glutamate transporters in astrocytes. J Neurochem 130:668-677. CrossRef Medline

Vasington FD, Murphy JV (1962) Ca ion uptake by rat kidney mitochondria and its dependence on respiration and phosphorylation. J Biol Chem 237:2670-2677. Medline

Volterra A, Liaudet N, Savtchouk I (2014) Astrocyte Ca(2) (+) signalling: an unexpected complexity. Nat Rev Neurosci 15:327-335. CrossRef Medline

Wan B, LaNoue KF, Cheung JY, Scaduto RC Jr (1989) Regulation of citric acid cycle by calcium. J Biol Chem 264:13430-13439. Medline

Wang GJ, Jackson JG, Thayer SA (2003) Altered distribution of mitochondria impairs calcium homeostasis in rat hippocampal neurons in culture. J Neurochem 87:85-94. CrossRef Medline

Wang X, Schwarz TL (2009) The mechanism of $\mathrm{Ca}^{2+}$-dependent regulation of kinesin-mediated mitochondrial motility. Cell 136:163-174. CrossRef Medline

Williams DC, Bejjani RE, Ramirez PM, Coakley S, Kim SA, Lee H, Wen Q, Samuel A, Lu H, Hilliard MA, Hammarlund M (2013a) Rapid and permanent neuronal inactivation in vivo via subcellular generation of reactive oxygen with the use of KillerRed. Cell Rep 5:553-563. CrossRef Medline

Williams GS, Boyman L, Chikando AC, Khairallah RJ, Lederer WJ (2013b) Mitochondrial calcium uptake. Proc Natl Acad Sci U S A 110:10479_ 10486. CrossRef Medline

Wong YC, Holzbaur EL (2014) Optineurin is an autophagy receptor for damaged mitochondria in parkin-mediated mitophagy that is disrupted by an ALS-linked mutation. Proc Natl Acad Sci U S A 111:E4439-E4448. CrossRef Medline

Zerangue N, Kavanaugh MP (1996) Flux coupling in a neuronal glutamate transporter. Nature 383:634-637. CrossRef Medline

Zhang Y, Chen K, Sloan SA, Bennett ML, Scholze AR, O'Keeffe S, Phatnani HP, Guarnieri P, Caneda C, Ruderisch N, Deng S, Liddelow SA, Zhang C, Daneman R, Maniatis T, Barres BA, Wu JQ (2014) An RNA-sequencing transcriptome and splicing database of glia, neurons, and vascular cells of the cerebral cortex. J Neurosci 34:11929-11947. CrossRef Medline 